\title{
“IT’S A STRUGGLE BUT IT’S ALSO A STRENGTH”: EMBODIED DECLARATIONS OF RESISTANCE, RESILIENCE, AND STRENGTH AMONGST SURVIVORS OF GENDERED VIOLENCE
}

by

Nicole Fontyn, BA, University of Toronto, 2012, BSW, Ryerson University, 2018

\author{
An MRP \\ presented to Ryerson University \\ in partial fulfillment of the \\ requirements for the degree of \\ Master of Social Work \\ in the Program of \\ Social Work
}

Toronto, Ontario, Canada, 2019

(C) Nicole Fontyn 2019 


\section{AUTHOR'S DECLARATION FOR ELECTRONIC SUBMISSION OF A MRP}

I hereby declare that I am the sole author of this MRP. This is a true copy of the MRP, including any required final revisions.

I authorize Ryerson University to lend this MRP to other institutions or individuals for the purpose of scholarly research

I further authorize Ryerson University to reproduce this MRP by photocopying or by other means, in total or in part, at the request of other institutions or individuals for the purpose of scholarly research.

I understand that my MRP may be made electronically available to the public. 


\begin{abstract}
“It's a struggle but it's also a strength": Embodied declarations of resistance, resilience, and strength amongst survivors of gendered violence
\end{abstract}

\title{
Master of Social Work, 2019 \\ Nicole Fontyn \\ Program of Social Work, Ryerson University
}

This study explores women's representations and declarations of resilience, resistance, and strength within the context of gender-based violence through photography. A visualnarrative methodology is used to answer the following research question: In what ways do survivors resist gender-based violence at both individual and systemic levels? Photo-elicitation interviews were conducted with a total of three female survivors between the ages of 27 and 35 living in the GTA. The benefits of this study involve reconceptualizing women's experiences of gender-based violence through creative expression, as well as disrupting dominant ideas of female survivors as "vulnerable victims" by constructing new accounts that depict strong, resilient women. The hopeful outcome of this study is that it informs current and future policy and practice. I hope that scholars, practitioners, and legislators will critically reflect on how their current and past research and practice may fall short of the rights and needs of women they work alongside. 


\section{ACKNOWLEDGEMENTS}

I would first like to acknowledge two extraordinary professors at Ryerson, Dr. Ken Moffatt and Dr. Purnima George. Ken, thank you for introducing me to the intersection of art and social work practice. Purnima, thank you for your kindness and endless support throughout my years at Ryerson. You both have inspired me in more ways than you will ever know.

I would also like to express my sincere appreciation to my research supervisor, Samantha Wehbi, for her ongoing support and guidance throughout this process. Without her patience, flexibility, creativity, and feedback, this research would not be possible. She represents the quality of instruction that every student only dreams of.

A big thank you goes to Nneka MacGregor, Shelleena Hackett, and the wonderful group of women at WomenatthecentrE for giving me purpose, for allowing me to bring my insights from this research into practice, and for providing me with alternative critical perspectives that have shaped the framework of my research.

Thank you to my life partner, Jordon Taylor, for continuously encouraging me to reach for the stars. Words cannot describe how appreciative I am to have you in my life. I love you.

Most importantly, I am forever grateful to the three women who dedicated their time and energy sharing their photographs and narratives for the purpose of this research. I am appreciative for their strength to open up their lives to me. Thank you! 


\section{DEDICATION}

This research is dedicated to the many women who have experienced or are currently experiencing violence in their lives. You are not alone and it is never your fault. You are brilliant, you are inspirational, and you are powerful. 


\section{TABLE OF CONTENTS}

Chapter 1: Introduction \& Theoretical Framework

Page 1

Chapter 2: Literature Review

Page 11

Chapter 3: Methodology

Page 22

Chapter 4: Findings \& Discussion

Page 27

Chapter 5: Conclusion

Page 54

Appendices

Page 56

References

Page 84 


\section{LIST OF APPENDICES}

Appendix A - Participant Photos \& Descriptions

Appendix B - Consent Form

Appendix C - Recruitment Flyer

Appendix D - Recruitment Email Script

Appendix E - Interview Guide

Appendix F - Participant Resources

Appendix G - REB Approval Letter
Page 56

Page 69

Page 75

Page 77

Page 79

Page 81

Page 84 


\section{LIST OF FIGURES}

Figure 1.0 Madison

Page 28

Figure 2.0 Lisa

Page 31

Figure 3.0 Destiny

Page 35 


\section{CHAPTER 1. INTRODUCTION \& THEORETICAL FRAMEWORK}

Despite the growing body of research and policy work aimed to eliminate gendered

violence globally, women continue to experience violence at staggering rates at both individual and systemic levels (Corcoran \& Lane, 2018). It has been found that approximately one in three women will experience violence in her lifetime; however, this number is likely significantly higher given that this ratio is determined by reported gendered violence, disregarding the fact that many women do not report due to systemic injustices, such as the reduction in government spending for social services (Morrow, Havinsky \& Varcoe, 2004), victim-blaming and motherblaming that are based on sexist and racist stereotypes (Ajandi, 2011; Humphreys \& Absler, 2011; Jackson \& Manix, 2004; Mandel, 2010; Pajak, Ahmad, Jenney, Fisher \& Chan, 2014), immigration policies, and the feminization of poverty (McInturff, 2013). I argue that the inability to combat gender-based violence is, in part, due to the ways in which society, including researchers, practitioners, and justice players, understand and attempt to combat gendered violence. The majority of existing research, social service agencies, and social justice initiatives tend to solely focus on women's oppression and victimization, ignoring the many ways in which survivors exercise power. In Hollander's (2005) words, this is an "unintended consequence of feminist struggles to heighten awareness of inequality and domination" (p. 777). This focus is problematic because it can lead to misrepresentation, further marginalization, and disempowerment, as it reinforces gender stereotypes that associate femininity with passivity, weakness, and vulnerability (p. 777-780). Soyini Madison (2005) argues that representation is critical in research and practice because "how people are represented is how they are treated" (p. 4). To extend this further, (mis)representation also directly impacts how women view themselves (McKenzie-Mohr \& Lafrance, 2017). 
We currently live in a neoliberal political state whereby large social service cuts have been made and values of individualism and self-sufficiency are favoured. This means that social issues are viewed as a result of individual failures and, due to this, there has been a push for the privatization of services (Morrow et al., 2004). Morrow et al. (2004) argue that this is particularly dangerous for women who have experienced or are experiencing gender-based violence. In Ontario specifically, there has been an increase in criminal justice measures and police-based programs to address violence against women at the expense of community-based services that are founded on intersectional feminist and anti-oppressive approaches. These shifts are concerning given that only one in ten women actually report their abuse. In the context of gendered violence, neoliberalism individualizes this social issue and supports 'victim'-blaming approaches, which assume women are at fault for the violence perpetrated against them (Morrow et al., 2004). I believe that these are blatant examples of systemic violence that heighten the violence that women already experience. Despite these forms of discrimination, however, women continuously resist violence at individual and systemic levels, which often goes unnoticed. My research aimed to disrupt the dominant discourse of vulnerability and victimhood of female survivors of violence by respositioning and reconceptualizing their experiences. This research centres women's declarations of resistance, resilience, and strength through photography, textual reflection, and narratives.

This study is directly influenced by an opportunity provided by Dr. Ken Moffatt in my fourth-year Bachelor of Social Work practicum seminar class. Rather than completing an extensive research paper, Dr. Ken Moffatt allowed students to create an arts-based project that incorporated course readings. Due to my own lived experience of gendered violence and the subsequent injustices I encountered while accessing services, I was motivated to conduct an 
arts-based project that presented survivors' resistance through photography. A total of 23 women from all over the world submitted photos of objects, places, and artwork that represented their own unique story of resistance as it relates to their experiences of genderbased violence. Participants also provided a brief description of how each photo represented resistance to them. My current research builds on this past experience by also relying on a photo-based approach; in this study, photographs are used to facilitate and enrich women's narratives of resistance, resilience, and strength. I hope that through my research, academic scholars, practitioners, and legislators will feel empowered to engage in critical reflexive practice to analyze how their current and past research and practice may fall short of the expectations, rights, and needs of women they work alongside. I hope to create opportunities for survivors to confidently exercise power in ways that shift how people, including themselves, think about women who have experienced violence. As McKenzie-Mohr and Lafrance (2017) say, "unpacking and deconstructing serve to 'make the invisible visible', such that we can make more intentional choices about how we story our lives" (p. 199).

\section{Theoretical Framework}

Positioning myself within my research is important to understand why I have not only selected my topic of resistance, resilience, and strength within the context of gender-based violence, but also why I have selected a post-structural feminist framework as the lens through which I will be viewing this topic. My personal relationship to this study is that I am a survivor of sexual violence and intimate partner violence (IPV). The first time I shared my experiences was as a participant in a community arts-based research project at Ryerson University alongside other survivors, which initiated my healing process and, for the first time, made me feel valued, something I had never really felt before. Prior to my participation in this project, I felt devalued 
by the criminal justice system that told me my assault did not warrant a report, the policies that prevented me from accessing support, and the general responses to violence against women made by the wider community. While these are experiences that have been traumatizing and have negatively impacted my life, they have given me the strength and compassion to support others who have also experienced gendered violence.

In my professional roles working alongside other survivors, I began to realize and, in turn, critically interrogate my privilege as a white, Canadian-born, heterosexual, cis-gendered woman. In my personal and professional experiences, I have learned about the many systems and structures that impact women's experiences in different ways, as well as impede particular women's abilities to leave a violent relationship and/or access supports and services. I, therefore, recognize that my narrative is more likely to be heard, supported, and advocated for simply based on the spaces and positions in which I occupy. Through my years of extensive engagement with scholarship, policies, and practices in the area of gender-based violence, I have come to realize that the main focus tends to be on women's oppression, trauma, and victimization, which I argue can be detrimental to female survivors. This is the reason why I wanted to shift the focus away from solely highlighting the negative impacts and challenges towards recognizing and centring the ways in which they resist these dominant discourses.

It is important to note that I intentionally use the term 'survivor' rather than 'victim' throughout my paper. The reason for this is that 'survivor' reflects the strength and resistance that so many women have demonstrated in their lives, which are often overlooked. I also deliberately use the term 'declarations' rather than 'stories'. Through my work with WomenatthecentrE, a survivor-led non-profit organization that works to eradicate violence against women through political and social advocacy, I was informed that participants of their 
larger research study for their Due Justice for All initiative resisted the term 'stories' because it insinuates that their experiences were fabricated, feeding into the dominant discourse that women exaggerate, dramatize, or falsify sexual assaults (Hackett, personal communication, January 24, 2019). WomenatthecentrE's project coordinator and Ryerson University alumni, Shelleena Hackett, carefully and critically considered this feedback from participants and, consequently, used the term 'declarations' as a way of reframing the way we think and talk about survivors' experiences. I hope to do the same through my work.

Gender-based violence is a broad concept. It involves the use and abuse of power and control over another person based on their gender identity, expressed gender, or perceived gender. Gender-based violence against women is a specific form of gendered violence that is targeted towards women-identified folks (Aghtaie \& Gangoli, 2014); however, for the purpose of this study, these two terms will be used interchangeably. In the context of this study, genderbased violence is defined as any form of violence (physical, emotional, verbal, psychological, financial, sexual, and/or systemic) perpetrated against women (Heise, Ellsberg \& Gottmoeller, 2002).

Post-structural feminism developed out of postmodernism, a theoretical framework that aims to challenge positivist conceptions of objectivity, truth, and power (Pierce, 2010, p. 37). Postmodernism is a theoretical framework that aims to deconstruct and reveal hidden structures; and art can follow postmodernist frameworks (Damianakis, 2007; Moffatt, in press). This approach recognizes that there are multiple interpretations and explanations, and values all of these as 'truths' for those who accept them. Postmodernism also views social reality as complex, fluid, and constantly changing, which challenges reductive and rationalist theories that assume reality as static and fixed (McArdle, Knight \& Stratigos, 2013; Moffatt, 2010). This 
invites us to question hegemonic discourses and recognize the multiplicity of voices and experiences within our current socio-political contexts.

Social work research and art can be understood as instruments of social change (Gray \& Schubert, 2010, p. 2310) that have transformative potential (Damianakis, 2007; Vacchelli \& Peyrefitte, 2018) due to their ability to "interlink our smallest personal gesture with the broadest concerns of social justice" (Moffatt, in press, p. 189). This research is greatly influenced by Christi Belcourt (2017), an Indigenous artist who captures and analyzes photos through the lens of Indigenous frameworks. I had the pleasure of attending one of her presentations at Ryerson during Social Justice Week. During this presentation, Christi argued that knowledge is the language (Belcourt, 2017). She demonstrated, through the presentation of photographs, the ways in which the words within the Anishinaabe language are verb-based and signify action, in comparison to the English language whereby words are mostly noun-based, merely objects or static "things". Christi's presentation came to the forefront of my mind when thinking about my research topic and, I would like to give credit to her and her work for inspiring my research focus. The research process will be guided by Christi's work to show how participants' photographs are not merely "static representations", but rather representations of action through their visual narratives of resistance, resilience, and/or strength.

According to Becky Francis, post-structuralism has helped "feminists to see that subject positions are multiple, and that shared womanhood does not necessarily equate with shared experience" (as cited in Pierce, 2010, p. 37). Drawing on this post-structural feminist approach, my research will incorporate an intersectional lens to recognize the unique experiences of oppression and resistance dependent on how other identities (e.g. race, class, sexuality, etc.) intersect with gender, which are socially, historically, and politically produced. The theory of 
intersectionality, developed by Kimberle Crenshaw, is a framework and analytical tool to understand the multiple, fluid intersecting identities, and the ways in which these intersections create unique experiences of oppression and privilege (Association for Women's Rights in Development, 2004). This critical framework will allow readers to understand the complexities of violence against women and remind them to take into account the full context of survivors' identities and experiences.

Post-structural feminist theory criticizes modernist understandings of power (Pierce, 2010) that presume power as a commodity that is entrenched in social systems, and that the identity of 'womanhood' is fixed and unchanging (Morley \& Macfarlane, 2012, p. 690). Specifically, post-structural feminism adopts a Foucaudian theory of power, which deconstructs rigid binaries of "powerful" and "powerless", as it allows us to see the many ways power operates, including strategies people use to resist repressive forms of power (Strega, 2005, p. 120). Foucault argues that power is exercised, not possessed; that power is repressive and productive; and that power comes from the bottom up (Fook, 2012, p. 56). In this sense, power arises from social, political and historical contexts, rather than one's "structural location." This theory also challenges the idea that power solely comes from the top-down by recognizing the ways in which members of 'oppressed' groups, such as women, resist dominant groups and discourses (Morley \& Macfarlane, 2012, p. 691). This is imperative when talking about or working with female survivors of gender-based violence because it disrupts dominant discourses that construct women as 'weak' and 'passive'. Due to this reason, my research presents counterdiscourses (McKenzie-Mohr \& Lafrance, 2017) that centre women's declarations of resistance, resilience, and strength. In this study, participants' declarations of 
resistance, resilience, and strength suggest that these concepts are interrelated rather than mutually exclusive.

Drawing on Frohmann (2005) and Crann and Barata (2016), I use resilience, resistance, and strength as broad and inclusive constructs to allow women the freedom to define the meanings and their importance in relation to their experiences rather than relying on narrow conceptions of these terms. Current conceptualizations of resistance in the literature on gendered violence are constricting. Many scholars make a sharp distinction between types of resistance strategies that imply that 'physical' strategies are considered superior to other strategies. For example, Edwards et al. (2014) distinguish between 'assertive' resistance strategies (e.g. physically fighting back, screaming, running away) and 'passive' resistance strategies (e.g. crying, trying to reason with the perpetrator, freezing), arguing that 'assertive' resistance strategies lead to more "positive outcomes" for sexual assault survivors (p. 2528). Similarly, Hollander and Rodgers (2014) categorize resistance into four categories: (1) forceful physical resistance (e.g. kicking, pushing), (2) non-forceful physical resistance (e.g. blocking or fleeing), (3) forceful verbal resistance (e.g. yelling), and (4) non-forceful verbal resistance (e.g. pleading or reasoning). While these categories do highlight resistance strategies, they suggest that more direct strategies are superior to other strategies utilized. They also exclude many other forms of resistance that women use, such as silence (Bhattacharya, 2009), safety strategies (Frohmann, 2005), social support (Jacinto, Turnage \& Cook, 2010), and spiritual coping (Drumm et al., 2014; Jacinto et al., 2010). Therefore, for the purpose of this study, resistance is broadly defined as exercising power in any way (through action or inaction) that opposes and challenges gender-based violence and the dominant discourses associated with it (Crann \& 
Barata, 2016). Defined in this way, women's declarations of resilience and strength could also be broadly understood as strategies of resistance.

McKenzie-Mohr and Lafrance (2017) use the broader term of "living well" (p. 195) as opposed to resilience. They argue that existing literature on resilience within the context of gendered violence is conceptualized as 'thriving' or achieving positive outcomes after difficult circumstances, which tend to abide by a very narrow understanding of what is actually considered a 'positive outcome'. Using 'living well' “creates space to allow participants to 'story' their experiences in potentially new ways" (p. 195). My research will follow a similar approach to avoid essentializing resilience and standardizing 'appropriate outcomes'.

The literature on gender-based violence defines survivors' 'strength' in various ways; however, most studies seem to associate strength with empowerment and healing (Drumm et al., 2014; Frohmann, 2005; Pyles \& DeChiro, 2012; Stevenson \& Allen, 2017). According to Stevenson and Allen (2017), "empowerment is a general feeling of competence, strength, and ability to succeed", which they argue promotes self-compassion. Wood (2015) claims that empowerment occurs when women recognize that they are the experts of their lives and that they have multiple strengths and skills that can be used to resist. I follow a similar definition, but embrace a holistic understanding of strength. For the purpose of this study, strength is broadly defined as physical, emotional, spiritual, and/or social strategies, resources, and/or skills that women used to empower themselves.

In what follows, I proceed to a discussion of the literature (Chapter 2) to highlight recurring themes, as well as gaps or limitations of existing studies and the ways in which my research attends to these gaps. I then outline the visual-narrative methodology used in this study (Chapter 3). I have combined both the findings and discussion (Chapter 4) where I highlight the 
uniqueness of the women's visual narratives. I conclude with a brief discussion of the strengths and limitations of this study, and the implications for social work practice (Chapter 5). 


\section{CHAPTER 2. LITERATURE REVIEW}

My quest for existing research on the topic of my MRP began broadly with a search using key words, such as "gender-based violence" and "violence against women", which allowed me to explore journals such as, Violence Against Women, the Journal of Interpersonal Violence, and the Journal of Women and Social Work. Through examining the literature, I have found that most of these studies (1) are situated within a positivist paradigm, and/or (2) heavily focus on the challenges that survivors experience within the context of gendered violence.

These 'efforts' are highly problematic because they not only perpetuate gender stereotypes, but they also decontextualize and essentialize participants' experiences, disregarding the complexity of women's lives based on their subject positions. Through extensive engagement with the present literature on gendered violence, three key themes emerged: (1) risk (Goodman, Dutton, Vankos \& Weinfurt, 2005; Jaquier, Fisher \& Johnson, 2011; Pedersen, Malcoe \& Pulkingham, 2013; Romans, Forte, Cohen, Du Mont, \& Hyman, 2007), (2) challenges and barriers (Johnson, 2017; Kumar, Nizamie, Srivastava, 2013; Pajak et al., 2014; Pyles \& DeChiro, 2012), and (3) resistance, resilience and survival (Crann \& Barata, 2016; Duffy, 2015; Drumm et al., 2014; Frohmann, 2005). Each of these themes will be further discussed below.

\section{Main Themes from the Literature}

\section{Risk}

Research studies on gender-based violence have largely been conducted using quantitative methods situated in the discourse of 'risk'. For example, in a cross-national study on physical and sexual violence against women by non-intimate partners, Jaquier et al. (2011) analyze surveys using a criminological perspective to discuss risk factors that are common amongst all countries studied. These include young age (under the age of 25), unemployment, 
and a history of victimization. They concluded that past experience of violence is the "strongest predictor of subsequent sexual and physical assault" (p. 412). Similarly, Romans et al. (2007) use data collected from the General Society Survey (GSS) with the goal of painting a 'picture' of the most 'at risk' for intimate partner violence (IPV), so that practitioners are better 'prepared' to work with the "most vulnerable" (p. 1497). The researchers found that being female, Aboriginal, and single along with having lower annual household income, children in the household, and poor health 'strongly' increase the likelihood of experiencing IPV. Both of these studies directly comment on the methodological limitations of using qualitative research methods for understanding violence against women. Specifically, they note the importance of generalizability in research to not only better understand the prevalence of gendered violence, but to also gain legitimacy in the literature. In this way, quantitative research is viewed as the preferred methodology for this topic.

Other studies have attempted to look at the intersections of race and gender, but due to the methodologies selected and the lack of critical analyses used to understand multiple systems of oppression, racialized communities have been constructed as 'predisposed' to gendered violence either as perpetrators or as victims. A controversial study conducted by three white female scholars, Pedersen et al. (2013), uses statistical analyses of a nation-wide survey to compare post-separation domestic violence amongst Aboriginal and non-Aboriginal women in Canada. Through analysis of the survey data, they found that Aboriginal women are four times more likely than non-Aboriginal women to experience post-separation violence, and this can apparently be explained by greater use of "coercive control" by Aboriginal men (p. 1044-1045). The authors directly state that they draw on a structural violence theoretical framework to understand the discrepancy between Aboriginal and non-Aboriginal experiences of post- 
separation violence, yet there is no mention of the impacts of colonialism on Aboriginal populations. It is clear that this research was guided by Eurocentic epistemologies that not only centre the researchers' agenda, but also exploits Aboriginal populations. Without an intersectional analysis that is socially, historically, and politically situated, Aboriginal communities are reconstructed as inherently "violent", "backwards", and "barbaric" (Coholic, Cote-Meek, \& Recollet, 2013).

Goodman et al.'s (2005) longitudinal study on protective and risk factors for "helpseeking” African American women found that high levels of social support can act as a protective factor with the exception of participants who experienced more severe forms of violence. They also found that strategies of resistance used by participants actually put women more at risk of experiencing abuse again. According to these researchers, risk of experiencing violence can be 'carefully' calculated in terms of probabilistic measures. For example, they argued that participants with low levels of social support "had sixty-five percent predicted probability of re-abuse during the next year" (p. 311-314). Despite the fact that the authors note the importance of reframing research on violence against women to include strategies women use to keep themselves safe, their research focus completely fails to do so. Their findings and discussion suggest that the level of risk an African American woman experiences is solely her responsibility by gaining social support while avoiding resistance to violence. In addition, resistance is only discussed within the context of physically resisting violence, ignoring the many other ways women understand and demonstrate resistance.

These research studies are positioned within a positivist paradigm given their choice of solely using quantitative methods to identify and measure 'risk' factors associated with gendered violence. Specifically, the majority of these studies rely on nation-wide surveys as 
their method of data collection, which typically only reflect reported gender-based violence, disregarding the fact that most women do not report the violence they experience (Morrow et al., 2004, p. 366). This approach to research also tends to individualize and decontextualize the experience of violence, ignoring history and the systems and structures of oppression that contribute to violence against women. This mirrors a neoliberalist ideology, which assumes individual responsibility for social problems rather than analyzing context and power relations that influence them (Gray, Dean, Agllias, Howard \& Schubert, 2015). I argue that this is particularly problematic for research on this topic, as it supports victim-blaming approaches whereby women are viewed as the source of their problem, which further adds to the violence women already experience.

Research that solely relies on quantitative data continues to silence survivors because it does not create space for women to voice their declarations and experiences. Rather, experiences are reduced to numbers, probabilistic measures, and cause/effect relationships for the purpose of explaining risk and protective factors for gender-based violence. The use of surveys does not account for the complexity of women's experiences and interpretations of gendered violence and resistance, and do not create space for a more nuanced understanding of these topics (Edwards et al., 2014).

\section{Challenges and Barriers}

Challenges and barriers experienced by survivors of gendered violence are discussed in various ways within the literature. These include the impacts of violence on women's mental health (Kumar et al., 2013), systemic violence when accessing support (Johnson, 2017; Pajak et al., 2014), barriers to leaving an abusive relationship, and control tactics used by perpetrators (Pyles \& DeChiro, 2012). Many of the research studies that I found that highlights the 
challenges and barriers that survivors experience typically utilizes qualitative research methodologies to centre women's voices.

Pajak et al. (2012) completed one-on-one interviews with the purpose of understanding survivors' 'stories' of accessing intimate partner violence-related services and supports. Many participants noted that they felt that service providers were coercive and abusive in that the "power differential within their relationship was exploited" (p. 2578). Participants also felt that service providers perpetuated victim blaming where they were made to feel that the abuse they experienced was their fault. Due to this, they said that they felt shame and embarrassment. In addition, the researchers found that participants experienced feelings of personal loss (emotional, financial, employment, housing), as well as relationship strains between their children and themselves. Similarly, Johnson (2017) highlighted women's stories of police interactions while reporting sexual violence. She found that police demonstrated disbelief and skepticism that blamed the 'victim', and that police were unaware of the effects of trauma, leading them to question the credibility of survivors. Overall, Johnson found that participants did not feel as though a respectful, compassionate response to the sexual violence they experienced was provided.

Kumar et al. (2013) discuss the consequences of gender-based violence on women's mental health. They found that experiences of gendered violence are associated with depression, anxiety, substance abuse, and damage to women's self-worth. The researchers found that almost all cases of gendered violence had experienced post-traumatic stress disorder (PTSD), which demonstrates the severe implications of violence for women. They also note that violence against women can lead to "premature death" (p. 5), which they argue requires more attention in scholarship and in practice. 
As argued by Strega (2015), qualitative research should not be free from criticism, as many critical studies have Enlightenment epistemological underpinnings due to the use of methodologies that tend to uphold inequities (p. 127-128). Kumar et al.'s (2013) study warrants criticism due to its rigorous nature. They use case studies written from the perspective of health practitioners to highlight the impacts of gendered violence on women's mental health. While these case studies show the devastating impacts of violence on women's mental wellbeing, they are outlined and analyzed in a technocratic and linear way that does not give way to the complexity of the participants' experiences, nor does it include the voices of the women the studies are about.

Existing research tends to construct female survivors of violence as weak, vulnerable, and powerless by focusing solely on the challenges and barriers they experience. While these studies offer meaningful insight about the many injustices that survivors of violence endure, they present a rather simplistic representation of their experiences that overlook the resistance, resilience, and strength that are exercised at both individual and systemic levels. As stated earlier, blatantly ignoring women's resistance has implications. Not only do these master narratives feed into gender stereotypes, but they also directly construct the ideas survivors have about themselves. As stated by McKenzie-Mohr and Lafrance (2017), “The stories we tell of ourselves and that are told of us construct our sense of self" (p. 191).

\section{Resistance, Resilience and 'Survival'}

Focus on resilience, resistance, and survival have made its way into more recent research on gendered violence, but is not the central focus of the research (Crann \& Barata, 2016; Drumm et al., 2014; Duffy, 2015; Pyles \& DeChiro, 2012). For example, Duffy (2015) uses a Sustainable Livelihoods (SL) framework to explore single mothers' experiences of 
transitioning into "sustainable livelihood" after leaving an abusive relationship. Within this framework, capabilities, assets and activities are assessed within five elements: (1) human capital, (2) social capital, (3) physical capital, (4) financial capital, and (5) natural capital. A sustainable livelihood is established when one "can cope with and recover from stresses and shocks and maintain or enhance its capabilities and assets" (p. 404). With the use of this framework, Duffy has equated resilience with sustainable livelihood and, thus, has conceptualized 'resilient women' as “good survivors” (Fraser \& Jarldon, 2015, p. 169; Pajak et al., 2014, p. 2581). This suggests that female survivors are 'resilient' only if they 'successfully' leave and stay out of an abusive relationship. It also suggests that 'resilient' women are those who are able to 'recover' or 'heal' from the abuse they experienced, ignoring the fact that violence can 'stay with' survivors years after, if not for the rest of their lives (McKenzie-Mohr $\&$ Lafrance, 2017; Morrow et al., 2004). Standardizing conceptions of resiliency excludes the many other ways women may understand and demonstrate resilience and, in turn, further marginalizes survivors who do not fit this constructed category.

Drumm et al. (2014) completed one-on-one interviews to understand "spiritually-based survival and resilience strategies" utilized by female survivors of intimate partner violence (IPV). Participants stated that their relationship with God provided them with a lifeline when they needed it most and offered them dependability when they felt isolated. The researchers found that spiritual practices, such as reading the bible and prayer, acted as "resources for coping, hope, and even maintaining emotional and mental health" (p. 389). This study allowed me to recognize other ways of interpreting and conceptualizing resilience, resistance and strength, and reinforced the need to maintain broad and inclusive concepts in my research. My research will go beyond spiritually-based resistance, resilience, and strength to include a more 
holistic and inclusive understanding of these concepts that will allow women to define and interpret their significance themselves.

Many research studies on gender-based violence have attempted to highlight both the experiences of violence, as well as resistance or survival strategies used to combat these experiences; however, the findings discussed tend to contradict the purpose of the research studies. For example, Pyles and DeChiro (2012) indicated that they explored participants' challenges and forms of resistance used within the context of gender-based violence in Albany, New York. Many barriers and challenges were discussed, particularly the variety of tactics that perpetrators use to control their partners such as denying access to education, work, and financial and community supports, which make it "difficult to be self-sufficient" (p. 92); however, resistance was only briefly mentioned. The authors only briefly noted participants' refusal to be silenced as a major form of resistance despite their hopeful title, "Stories of Survival and Resistance".

Duffy (2015) and Frohmann (2005) incorporate photos into their research. Frohmann uses participant-generated photos and individual or group photo-elicitation interviews to explore women's 'stories' of resistance, and the ways in which they keep themselves safe. In this process, women were able to actively decide how and when to participate. Similarly, Duffy uses photovoice, a community-based research method, to examine single mothers' resilience after leaving a violent relationship. Her study was more directive in that she asked participants to photograph and keep field notes of their experiences along four areas of "livelihood assets". Duffy presents broad themes that emerged through group dialogue. Conversely, Frohmann notes the complexity and multiplicity of women's experiences and, therefore, themes were not discussed. Instead, she presents participants' photos along with their brief descriptions and 
written narratives that offer insight into the meanings of the photos. Photographs, as part of visual art, can be used as a tool for self-exploration, reflection, and analysis. In this way, photos can assist with the exteriorization of memories and emotions (Sinding, Warren \& Paton, 2014, p. 191). Indeed, Duffy (2015) and Frohmann's (2005) research demonstrate how art not only enables the expression of emotions, but also facilitates a process of knowledge and meaning making.

\section{Gaps}

It is clear that gendered violence has been extensively studied in scholarship; however, a gap in the literature exists regarding the ways in which survivors demonstrate resistance, resilience, and strength. Research continues to focus on survivors' struggles, vulnerability and victimization even when the focus is intended to be on resistance or resilience, erasing the ways in which survivors exercise power. Some studies have attempted to highlight women's resistance and resilience; however, they are conceptualized in very narrow ways. Resistance in research tends to be understood as solely 'physical resistance' (e.g. hitting, kicking, pushing, etc.), which ignores the many other ways that survivors define and demonstrate resistance. Conceptualizations of resistance also seem to be individualized. For example, resistance has been defined as "deliberately behaving in a certain way with the intention of mitigating future abuse" (Crann \& Barata, 2015, p. 860). Crann and Barata claim that defining resistance in this way is problematic because it appears to place the responsibility onto survivors rather than externalizing gendered violence to outside political forces. In addition, resistance and resilience literature on gender-based violence constructs and categorizes some women as "good survivors". Particularly, those who call the police on their perpetrators or are able to "successfully" leave and remain "free" from an abusive relationship are considered "ideal" 
survivors that are 'deserving' of justice (Fraser \& Jarldon, 2015, p. 169). This blatantly ignores contextual reasons why women do not report violence and/or leave an abusive relationship. These stereotypical constructs are contradictory to the purpose of narrative resistance (Crann \& Barata, 2015) because they do not attend to context nor do they "accommodate the plurality of meanings individuals negotiate in their self-constructions as resilient" (Ungar as cited in Crann $\&$ Barata, 2015, p. 856). Due to this, my research aimed to create space for women to reflect and act on their own understandings of resistance, resilience, and strength.

There remains a dearth of research that not only highlights the many ways that resilience, resistance, and strength are employed, but also the multiple interpretations of these concepts. My research draws on Frohmann's (2005) study that uses photography and narratives produced by female survivors of gender-based violence that depict the strategies they use to keep themselves safe. My research differs in that the central focus went beyond safety strategies to include the ways women define and demonstrate resilience, resistance, and strength in their lives. My research explored women's embodied declarations of resistance, resilience, and strength within the context of gender-based violence to challenge dominant discourses that construct women as 'vulnerable victims'.

Despite the value that other research has in highlighting experiences of violence against women using narrative and arts-based approaches, these two methodologies are rarely used collaboratively (Simmonds, Roux \& Avest, 2015). Wehbi (2012; 2015) argues that there has been little reliance on creative arts in social work due to the profession being dominated by evidence-based practices; however, she maintains that using art can challenge what is considered 'legitimate knowledge'. Art can offer many benefits within research. In our current precarious state, which is directly linked to neoliberalism and globalization, art may be required 
more than ever. Using art in research can provide participants with the ability to cope with and express difficult feelings, reflect on their positions within our contexts while building a sense of support, and engage in social justice and social change (Moffatt, in press). In this sense, my research, in itself, is a form of resistance. Simmonds et al. (2015) discuss the possibility of blurring the boundaries between visual, arts-based methodologies and narrative approaches to research to argue that using both can attend to the limitations of these methodologies when used individually. They argue that when only using photography in research, meanings are open to interpretation and can lead to misrepresentation. When narrative approaches are used alongside photography, participants can take control of how their photos are represented. Narratives, therefore, contextualize photographs and their meanings, offering rich insights into participants' lives and experiences, and the ways in which they relate to power relations. Narrative approaches can also open up space for participants to reflect on potential memories that are evoked during an interview (p.33-38). For this reason, participant-generated photographs will be used to facilitate women's declarations.

Using a visual narrative methodology, my research will seek to answer the following research question: In what ways do survivors resist gender-based violence at both individual and systemic levels? 


\section{CHAPTER 3. METHODOLOGY}

For the purpose of my research, I used qualitative research methods to attain rich understandings and interpretations of women's resistance, resilience, and/or strength within the context of gender-based violence. This study utilizes a visual-narrative methodology (Frohmann, 2005) with the goal of centering survivors' declarations. A visual-narrative methodology incorporates 'storytelling' and visual art into the research process. Visualnarrative methodologies have been proven valuable for working with women because it aligns with and is situated in post-modern feminist research and practice. Specifically, visual-narrative methodologies incorporate and amplify alternative ideas, images, and voices that have been historically silenced in social and political spheres (Frohmann, 2005), as well as provide the means for the "uprising of subjugated knowledges" (McArdle et al., 2013). Most noteworthy is its compatibility with intersectional theory, as it creates space for multiple knowledges and interpretations (Lu \& Yuen, 2012; Vacchelli \& Peyrefitte, 2018). This is of particular interest because I hope to highlight the unique experiences and narratives of survivors of gendered violence based on their intersecting identities along the lines of gender, race, class, sexuality, citizenship, etc.

In this study, data collection methods consist of participant-generated photographs with a camera of choice and individual-elicitation interviews. Photo elicitation interviews incorporate photographs into the interview process to evoke various knowledges and discussions about the participants' lives as they relate to the larger social context (Frohmann, 2005; Rose, 2012). As argued by Rose (2012), the goal of photo-elicitation interviews is to explore the images and their meanings, as well as uncover social and historical production of power relations. Photo-elicitation interviews allow audience members to gain creative insight 
into photographers' lives (p. 299-312). This method of data collection also provides opportunities for participants to "reflect on their everyday activities in a way that is not usually done... and allows them to articulate thoughts and feelings that usually remain implicit" (p. 306). Many authors have discussed how photography and art can be very useful for individuals who have experienced trauma in their lives (Butterwick, 2017; Moffat, in press) due to the fact that "some experiences are below words" (Grassau as cited in Sinding et al., 2014, p. 191). Photo-elicitation interviews with female survivors of violence may not only facilitate an expression of emotions, but also facilitate therapeutic healing (Frohmann, 2005). The possibility for healing may be elevated in this study, as the main focus is on survivors' declarations of resistance, resilience, and strength rather than the ways in which they have been oppressed, discriminated against, and disempowered.

I interviewed a total of three women between the ages of 27 and 35 with lived experience of gender-based violence. Participants were recruited widely from my network via Facebook and an e-blast. Participants were given the opportunity to choose a pseudonym or remain completely anonymous throughout the study. All women selected pseudonyms to be used for the purpose of this research. These women go by the names of Madison, Lisa, and Destiny. I recruited participants from the Greater Toronto Area (GTA), as I travel to and from various cities throughout the GTA to visit friends, family, and colleagues.

Participants were asked to generate and select five photos that they believe best represent their declarations of resistance, resilience, and/or strength. After photos were taken, participants were asked to construct a brief reflective description of each photo prior to their interview. The purpose of these reflective descriptions was that participants were able to begin thinking about the ways in which their photos represent their experiences, which enriched the 
interview process (Rose, 2012, p. 311). Participants were then invited to participate in a 2-hour individual photo-elicitation interview that explored the relationship between participants' experiences, their photos, and the wider socio-political and historical contexts. These interviews were audio-recorded for the purpose of transcription to critically analyze participants' declarations, written reflections, and photos.

Rose (2012) discusses the importance of compositional and technological components of photographs. She argues that the technology used to construct photos, as well as the formal elements of the images, directly impact their meaning and effect (p. 20). Many scholars have argued that the key element of photo-elicitation interviews is not just the visual content of the photographs themselves, but also the ways in which they are interpreted (Rose, 2012, p. 299). Drawing on Banks (2001), I analyze the internal and external narratives of participants' photographs. Banks argues that the internal narrative consists of the meanings and interpretations of the image, which are shaped by experiences. Along with an analysis of both denotative (literal) and connotative (e.g. feelings, ideas, and representations) meanings of photographs, I also analyze the technological and compositional elements, and the ways in which these determine the meaning and effect of the images (Rose, 2012). The external narrative links the meanings and representations to the broader social context (Wehbi, 2017) as it relates to violence against women. A post-structural feminist theoretical framework will guide this discussion.

Butterwick (2017) discusses how art can facilitate imaginative reflection for not only the participants, but also the audience. She further argues that the interpretations of artwork shift depending on the audience and the context in which it is being viewed. This is similar to what Rose (2012) calls "the site of audiencing", whereby the audience can renegotiate the 
meanings attached to an image (p. 30). Given that research is never truly objective and, in turn, I can never fully separate myself from my research, I have also noted my own interpretations, feelings, and ideas for each of the three photographs discussed in this study. I am "implicated in the process of meaning-making" (McArdle et al., 2013, p. 361), as my relationships with the participants and my interpretations of their photos are impacted by the theoretical and epistemological underpinnings of my study.

Drawing on Braun and Clarke (as cited in Baker \& Lewis, 2013), I also use thematic analysis to present themes that emerged through the women's visual narratives. Coding began as I examined participants' images and read their interview transcripts in their entirety on three occasions, at which point additional codes could not be developed. I then grouped these codes into categories followed by collapsing them into themes.

\section{Ethical Considerations}

Prior to recruitment, I had hoped to interview four participants; however, due to time constraints, I was only able to interview three. An unforeseen technological challenge occurred during the final interview. Immediately after this interview and prior to departing, I had checked the recorder for the audio file, but did not listen to it. The file appeared to be on the recorder including the time of the recorded audio. Only after attending home did I attempt to listen to the file. To my surprise, the audio did not play despite the file being visibly present on the recorder. After many unsuccessful Google searches, I was unable to find a solution. I did not seek support from third parties, as the recorder potentially held confidential information. I informed this participant of the technological challenges via email, and she so graciously offered to redo the interview at a later date; she had stated that it was important for her to share 
her declarations of resistance. Cost of transportation to and from the interview, as well as an additional Walmart gift card were provided.

Many women showed interest in the study but did not have the time to dedicate to generating photos and attending an interview. Disposable cameras were made available to those who required them; however, all participants took digital photos using their cell phones or digital cameras. Due to confidentiality purposes, participants were asked to refrain from taking photographs of people or things that may identify them or others. One participant used a photo of her $\mathrm{PhD}$ diploma, as this best represented her declaration of resistance. To ensure confidentiality, her name was blacked out. All participants received a list of women's resources prior to their interview (please refer to Appendix F). An interview guide consisting of questions was used (please refer to Appendix E). At the end of the interview, participants were asked to select their favourite photo to be used as the central focus of the research. I had intended to critically analyze all images; however, as interviews began, I realized that this was beyond the scope of my paper. Therefore, a total of three photographs (one for each participant) are analyzed and discussed in this paper. All other photos, along with their reflective descriptions, will be included as an appendix in my final research paper (please refer to Appendix A). 


\section{CHAPTER 5. FINDINGS \& DISCUSSION}

I had the opportunity to sit down with three powerful women to explore their photographic representations of resilience, resistance, and strength within the context of their experiences of gender-based violence. I did not explicitly ask the women for their demographic information but, instead, allowed them the space to self-identify within their narratives. The women ranged in age from 27 to 35. Madison identified as East Asian, Lisa identified as mixed race, and Destiny identified as European and South American. All women identified as cisgendered. Destiny identified as bisexual and the other two women identified as heterosexual. Madison shared that she has one son and Lisa shared that she has two daughters. Madison and Lisa identified as being single parents raising their children separate from the father of their children.

In each interview, I asked the women about their experiences of gendered violence with the intent of providing context prior to introducing their images in this paper; however, Destiny challenged me when I asked her to share as much or as little as she wanted about the violence she endured. She stated, "I think I talked enough about my experiences of gender-based violence through my images. I really want to emphasize how I've resisted". I am grateful that she demonstrated this resistance because it allowed me to reflect on my research process and the ways in which this particular interview question potentially contradicts the purpose of my research: to demonstrate the ways in which survivors have resisted violence at both individual and systemic levels. Due to this, I have chosen to refrain from providing details of the violence they experienced separate from the photos within which the narratives emerge.

Due to the uniqueness of each of the women's embodied declarations of resistance (Pierce, 2010), I separately introduce each of their images and associated internal narratives of 
the images. I then move forward by presenting the external narratives by contextualizing each image using a post-structural feminist framework. I conclude this chapter by presenting and analyzing recurring themes that emerged through the women's visual narratives.

\section{Madison}

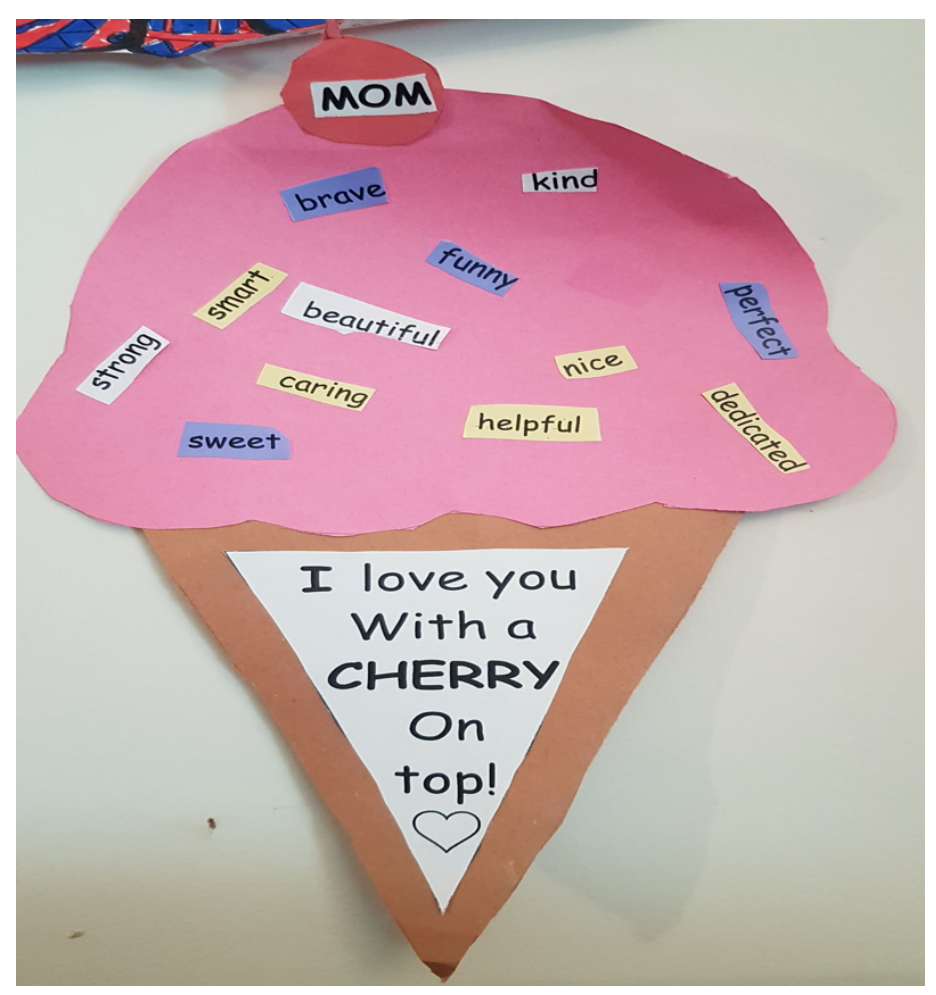

Figure 1.0

Madison had a difficult time selecting a photo that best represented her declaration of resistance because, to her, they all had equal importance. After much consideration, she narrowed her choice down to two: (1) the statue of a mother and her child placed in front of a birthday card from her son (see Appendix A, Photo 1) and (2) a Mother's Day card constructed by her son (Figure 1.0). To Madison, these photos were most important because her son has played an active role in her resistance. This is demonstrated when she stated, "If I didn't have him, I don't know where I would be today with my perspective of who I am." She asked for my help to select between the two and, together, we chose the homemade card from her son. 
Figure 1.0 is Madison's photo of a homemade Mother's Day Card that her son gave her. The card is cut and pasted into the shape of an ice cream cone with a cherry on top that says, "Mom." The base or cone of the card says, "I love you with a cherry on top!" Madison's son picked out words that he perceived his mother to be and glued them onto the ice cream portion of the card. These words include: strong, smart, brave, funny, kind, beautiful, perfect, nice, dedicated, helpful, caring, and sweet. Madison selected this photo because the card not only reminds her to think more positively about herself, but it also has helped her shift her entire perspective of who she is. Madison remarked,

It helps me change my perspective of who I am. Like, when my son showed or gave me this, I thought, 'You think I'm this?' And I get to reflect on it and how he talks to me and looks up to me. And it's just a hit in the face, like, 'Hey, I've been looking at myself so negatively.' And to look at this and think, 'No, I'm not all of those negative words I have labeled myself to be or others have labeled me to be.

Madison discussed how the family violence and domestic violence she experienced impacted her self-esteem and made her feel the opposite of the words her son chose to describe her. She contextualizes this by stating, "I was blamed for staying that long, and why I would do that. And I blamed myself up until like 9 years ago."

When I asked Madison about the technological and compositional elements of her image, she seemed somewhat confused because she had not thought about these components before. She stated, "I'm not artistic, so I don't know what to tell you." After some probing questions, she commented on the colour: "My son knows I love pink, which is why everything he gives me has pink. He will choose pink for me despite his class; they make fun of him all the time for pink because of gender norms and expectations." This not only demonstrates the 
pervasiveness of socially constructed gender norms at such a young age, but also her son's resistance of these expectations by continuing to select the colour pink for his mother, which is often times associated with femininity. Post-structural feminism challenges the notions of objectivity and 'truth', arguing that objectivity and a singular 'truth' do not exist and, therefore, there are multiple interpretations that can be regarded as 'truths' (Pierce, 2010). This approach supported me in my research process, allowing me to reflect on the participants' visual narratives to renegotiate their meanings based on my personal epistemology. In addition to the internal and external narrative of Madison's image, I was visually focused on the roughly cut edges at the bottom of the pink ice cream. Although I do think it was cut beautifully by Madison's son, I could not help but think that this could somehow represent the socially constructed dominant ideas around mother blaming and 'victim' blaming that are so harmful and violent. Yet, despite this violence, active resistance exists all around us to challenge these labels, discourses, and ideologies, just like these positive words that surround the card.

Madison's reflections are profound because they directly illustrate the ways in which the words chosen and placed on the card by her son facilitated Madison's reflection about who she perceives herself to be and, in turn, challenge the sexist discourses around 'victim'-blaming and mother-blaming. The current concept and experience of mother-blaming involves what Mandel (2010) calls "double standard of parenting expectations" (p. 531), which is deeply rooted in colonialism and, in turn, socially constituted, Eurocentric gender binaries that construct women as 'inherently' responsible for their children (p. 530). Similarly, victim-blaming discourses place the blame on the survivor rather than the aggressor (Pajak et al., 2014). In the context of intimate partner violence, the dominant responses to domestic violence, especially within child protection and health care, often blame, shame and discipline mothers for violence perpetrated 
by their abusers while failing to hold the abuser accountable (Ajandi, 2011). Madison's statement about being blamed for staying in an abusive relationship and the subsequent internalization of blame supports existing research that demonstrates the impact of discursive labels related to mother-blaming and victim-blaming on survivors' perceptions of themselves (Edwards et al., 2014; Humphreys \& Absler, 2011; Jackson \& Manix, 2004; Mandel, 2010; McLaren, 2012). While Madison's visual narrative declarations demonstrate the implications of repressive power, they simultaneously highlight her resistance to systemic violence through facilitated reflection regarding her son's perception of her and, in turn, her perception of herself. This supports a post-structural feminist approach because it deconstructs dichotomous categories of power that assume power as static and solely "top-down" (Cannon, Lauve-Moon \& Buttell, 2015).

\section{Lisa}

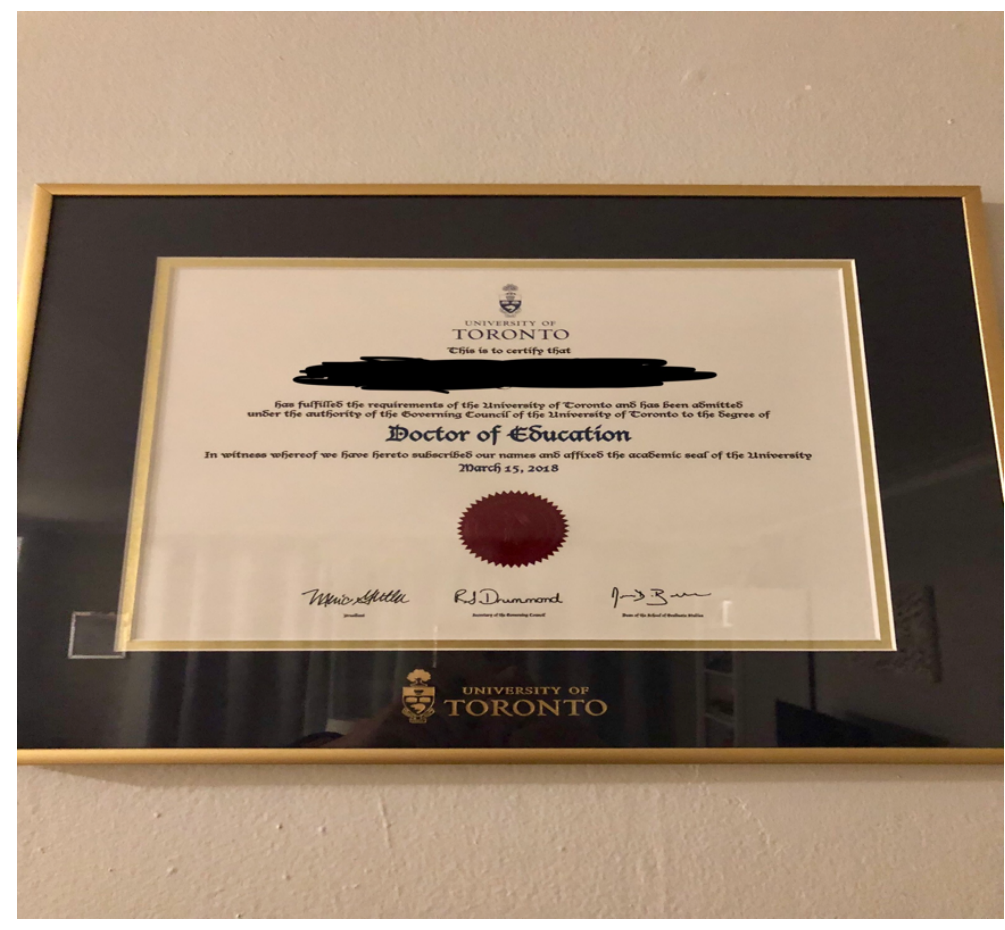

Figure 2.0 
Although Lisa recognized the importance of all of her photos, she chose the photo of her doctorate degree in Education from University of Toronto (Figure 2.0) because it encompasses elements she discussed through her other images, such as the love she has for herself and her daughters, her perseverance, and the strategies she used to resist violence. In our interview, Lisa shared that she specifically selected this photo because it shows that she continued to complete her doctorate degree despite what she had experienced and the negative messages she received from others. She stated,

For me, that was the testament to all of the struggles and finally being able to breathe and be like, 'Okay, I did it' and I reached where I wanted to get to and now I can just focus on work and keep building a life for my kids. I did it despite everything that I had been through and that having two children and being a single parent without money at the time, and people say, 'Oh, you're not going to do it; you can't do it, it's so hard especially as a single mother with no money', and 'How are you going to go to school for this long raising two kids on your own?' I recognized that this was a false construction related to the fact that I am a woman of colour, and that made me want it even more when people said I couldn't do it. Whenever people tell me I can't do something, it just makes me want to do it more.

Lisa continued to discuss how her aggressor, her children's father, was emotionally abusive towards her while she was completing her previous undergraduate and post-graduate degrees. She shared that he continuously told her she could not be a teacher because she was 'stupid', 'not very intelligent', and 'disorganized'. Due to this, she strategically refrained from telling him that she was completing Teacher's College at that time. She commented, 
That was a strategy because I had to be careful what I told him. It's resistance and survival really because I was trying to make a better life for my children by going to Teacher's College to get a decent career, and I didn't want him to do anything to stop me from getting that career, so he couldn't derail me and find a way to say that I'm a delegitimate mother.

When I asked Lisa about the technological and compositional elements, she commented on the word "Doctor" (Figure 2.0) and the way it is bolded to highlight the power that her abuser consistently tried to minimize. When I look at this photo, I see success and leadership, but not in the modernist sense whereby success equates to individualist notions of hard work and progress. Rather, this image conveys the strategies of resistance that Lisa utilized while she experienced violence and, in turn, dynamically shaped her into an excellent leader. She supports this when she stated, 'I think intelligence is not about how many degrees you have. I didn't do this to just prove a point. It was more that this was a way to protect myself and my daughters and my future." The dark blue border reminds me of the darkness that Lisa experienced and continues to experience. It has surrounded her, but it does not define her. The bright contrast in the middle represents who she truly is despite what and how others have labeled her. To me, the thin gold borders around the outside of the frame, as well as between the blue border and the white middle, represent her children who have given her purpose.

Scholars have argued that resisting gender-based violence is more comprehensive than self-defense; resistance can involve both action and inaction, challenging what many people believe 'resistance' means and entails (Cannon et al., 2015; Crann \& Barata, 2016). Lisa's declaration illustrates silence or refusal to inform her abuser as necessary for her survival, which simultaneously acted as an effective tool that challenged emotional violence and 
patriarchal discourses, such as the social construction of the "delegitimate mother" (Ajandi, 2011; McLaren, 2012). The same "silencing" of survivors that is used by aggressors, as well as social and political structures to uphold dominant discourses such as the "delegitimate mother," is being used by survivors themselves as a resistance tactic to unsettle the aggressors and structures that silence them (Bhattacharya, 2009). Lisa recognized the emotional violence her aggressor continued to perpetrate, which allowed her to strategize to survive. Thus, she remained silent about her education to allow her to finish her program without having to experience further violence from her abuser. She not only finished her Teacher's College, but she continued beyond this to attain her Master's of Education and her Doctorate in Education. Lisa's visual narrative also exhibits her resistance towards the social and political stigma associated with single motherhood. Specifically, single motherhood is socially, politically, and historically constructed in solely victimizing and pathologizing ways, and intersects with other social identities, such as race, class, and sexuality. As Ajandi (2011) states, "It is a deeply racialized image that presents a false and simplistic picture of a single mother dependent on social assistance" (p. 411). It is evident in Lisa's excerpt that others perceived her in this destructive light, especially as a racialized woman; however, she opposed this by recognizing this false construction and by continuing to attain her education despite violence at both individual and systemic levels. In this way, her embodied declaration acts as an alternative discourse that disrupts what it means to be a single mother who has experienced and is still experiencing violence. 


\section{Destiny}

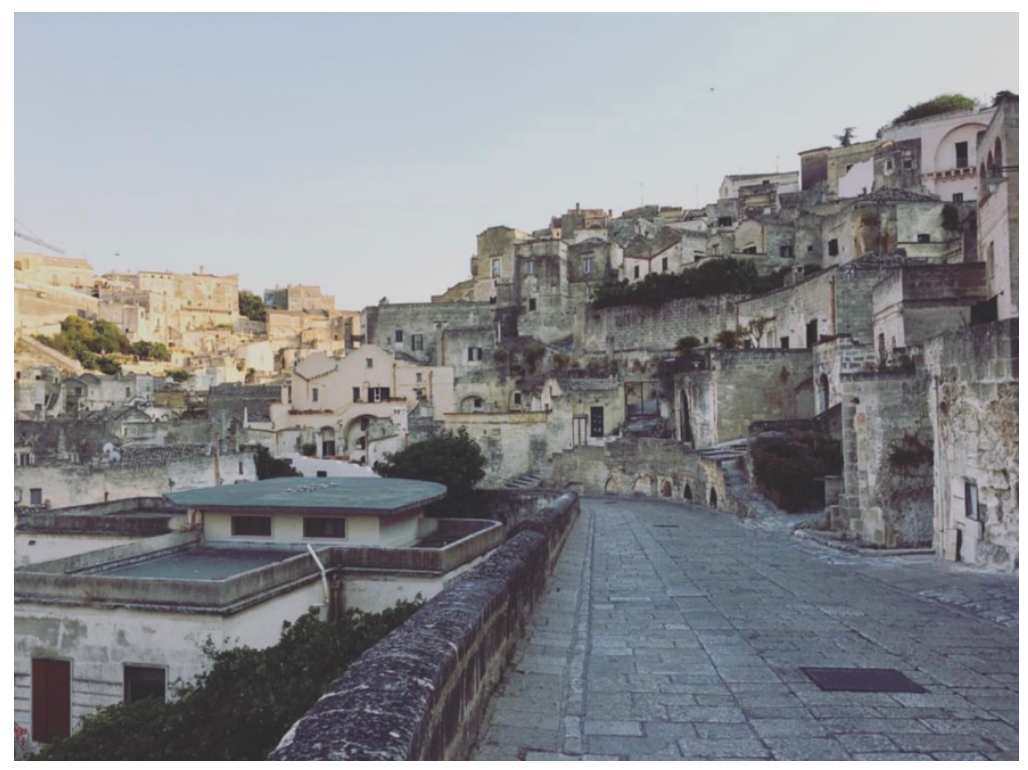

Figure 3.0

Similar to Lisa, Destiny selected this photo (Figure 3.0) as best representing her declaration of resistance, resilience, and strength because it highlights her photos' overarching theme of a matriarchal system operating within a patriarchally confined society. Destiny shared that she took this photo in 2017 when she went back to her maternal grandmother's home town in Italy. She described it as a town built out of stone within a mountain, mixed with 'old' and 'new' structures. She also pointed to the fact that her grandmother was born out of the mountain on the left-hand side of the photo where it is illuminated. To Destiny, this photo represents where she came from, as well as the safety her grandmother provides, and the lessons she delivers: "This image just shows me where I come from. It shows me how beautiful my grandmother is for creating such a safety net, creating such a beautiful home full of abundance of everything: of love, laughter, of communication, and lots of lessons."

Destiny said that her grandmother's home was a place of safety and hope for her and her family. She shared that her and her mother frequently fled to her grandmother's due to her 
father's ongoing violence throughout her life. She also stated that she fled there recently for approximately one month because of her step-father's violence towards her,

This was all imitations of what my mom was going through with my dad. So, I saw my grandmother struggle every time I came near and she told me, she goes, 'My poor granddaughter. I know you're struggle. You don't belong there; you don't belong there. Just know that you always have a space here.” And I said, 'I know'. She always makes me feel welcome. She makes me feel like she understands. She understands why I felt like I couldn't go back.

Destiny also discussed the importance of recognizing her grandmother's history of violence as the reason she escaped her town and came to Canada because it made her the strong person she is today. She shared that this violence and the passing of her grandfather required her mother and aunt to grow up very fast yet demonstrating their independence: "My aunt dropped out of school and my mom was working right out of high school, so these women really had to fight without the male figure."

In my interview with Destiny, she reached a moment of realization when reflecting on the technological and compositional components of her image that made her pause and reflect. As discussed above, she highlighted the importance of incorporating her grandmother's history of violence as the reason she fled to Canada where she started her family, and as a statement that shouted her autonomy and agency. Destiny commented on how this was mirrored in the technological and compositional elements of Figure 3.0:

(My grandmother) was like, 'No, I'm getting the fuck out! I'm going to live my life and I'm not going to live it in your shadow.' And I think that's so interesting to the composite because there's this huge shadow. There's a huge shadow overcasting the 
city, but where she grew up is the only part that's illuminated. That's freaky. She's not in anyone's shadow anymore. She's casted such a big shadow that now it's like we're under hers. Now there's so much to look up to, and it's not in the ways that my paternal side made me feel with the big beautiful house. My grandmother showed me, 'Honey you can make that big beautiful house.' And she did.

The first time I looked at this photo, I was drawn to the stone because I think it represents Destiny's strength and the strength of the women in her life that have provided her with safety and valuable life lessons throughout her life. It is almost like the strength transcended down to her mother, her aunt, and herself through the support and life lessons. Regardless of what is or may be happening environmentally, the buildings, the houses and monuments stand tall and strong. That's exactly what they did, and that's exactly what I have done in my experiences of violence.

Destiny's accounts of family violence she continues to experience exhibits nontraditionalist notions of independence as a strategy of resistance used by her and the women in her life. Chantler (2006) argues that the dominant discourses related to gendered violence imply that survivors who remain in abusive relationships fail to demonstrate autonomy and are dependent on their abusers, and only survivors who "successfully leave" are depicted as strong, independent women. The underlying message of this binary is that they are located within the person, ignoring the socio-political barriers that survivors of violence continue to face. This discourse is a direct result of neoliberalism and its value of individualism, which places the responsibility on survivors to "fix" themselves and become more "assertive" (Chantler, 2006; Morrow et al., 2004). Destiny's excerpt above suggests that despite social and political barriers, such as violence and the feminization of poverty (Bradshaw, Chant \& Linneker, 2017), the 
women in her life thrived and supported one another. In addition, Destiny spoke about the ongoing family violence and that her and her mother never really "successfully" left the abusive relationships but were able to temporarily flee violence when it escalated as a strategy to ensure safety. This challenges the dominant narrative that assumes survivors are only strong and "agents of change" when they leave "once and for all." Rather, survivors formulate and practice powerful tactics as violence arises, which are essential to their survival. Her visual narrative demonstrates that while temporarily fleeing violence to stay with her grandmother, she recognized the importance of physical safety (Frohmann, 2005) and the value of connectedness with the other women in her life (Chantler, 2006) as strategies of resistance.

\section{Main Emergent Themes}

Although each participant's selected image and their associated narratives are unique, eight major themes emanated from the interviews. These include: (1) self-love, (2) contextualizing violence, (3) resistance through action, (4) education as protection, (5) deliberate silence and conformity, (6) social justice and advocacy, (7) family supports, and (8) spirituality. These findings present strategies of resistance, resilience, and strength in ways that go beyond what is discussed in existing resistance scholarship, specifically within the context of gender-based violence. Through these themes, readers will be able to acknowledge the complex and nuanced realities of survival of gendered violence.

"I love myself enough to be alive and care about my life." The first main theme was around self-love, which was demonstrated in all of the women's visual narratives. I find that this is very powerful and is important to highlight given that existing scholarship on gendered violence tends to centre the negative impacts of violence on survivors' mental health and self- 
esteem (Kumar et al., 2013), ignoring the love and admiration women continue to have for themselves. Self-love was talked about in different ways and in different contexts, but they all recognized the love and care they have for themselves as strong women. Madison spoke about self-love as a great mother while recognizing the challenges of doing so because of systemic violence,

I am a great mother and I can do it despite everything that has happened to me and everything that people have said to me, and those things I have internalized. It went away because I can see what I am capable of doing, but it took a lot longer, because of those messages, for me to feel like a good mother.

Madison also spoke about self-love, but in terms of her mental health. She recognized the realistic challenges of loving herself on a day-to-day basis, but her love is strong enough to help her move forward in her life. She commented, "It's hard to love yourself let me tell you that much. There are days that I don't love myself, but I love myself enough to be alive and to care about my life. So, love is the foundation to everything I do." Similarly, Destiny commented on the struggle and hard work that is required to love herself,

The hard part is doing the work on the daily basis; that daily work of reminding yourself that you are fucking good enough and that you can do the work. That's the struggle and a lot of that struggle came from the violence I experienced. The hard part is telling myself the positive parts of myself and the strengths that I have. And I try to do that now. It's a struggle, but it's also a strength. Yes, I struggled, but that's resilience and strength.

Destiny's argument around self-love was strengthened when she talked about the love she has for herself in relation to her grandmother: "I definitely have my helping, my teacher's helping 
qualities from my grandmother, and this photo reminds me of her and of all the great things about myself. I love her and I love myself." Lisa also spoke about self-love, but in the context of her academic achievements and the pride she has for herself. She stated, "I got one of the eight spots to do this program. For me to finish it in three years was really good, really remarkable. I am really proud of myself and my thesis; writing is so empowering, and I google myself sometimes."

These reflections are incredibly insightful. They really illuminate the purpose of this research and break down dichotomous discourses that construct survivors as either "powerless victims" or the "ideal survivor" (Cannon et al., 2015; Fraser \& Jarldon, 2015; McKenzie-Mohr \& Lafrance, 2017). Yes, survivors struggle, but they also survive and thrive in these circumstances, a point that is rarely featured in gender-based violence research. In my review of the literature, self-love was rarely noted. One article by Stevenson and Allen (2017) discussed self-love as "self-compassion" or this ability to love oneself with a non-judgmental attitude despite hardship related to violence. Although the women's declarations support this finding that self-love occurs despite violence, it ignores any connection to external historical, social, and political contexts that label, shame, and blame survivors. Rather, self-love is conceptualized as this ability "to respond to personal inadequacies with kindness and equanimity" (p. 307), which perpetuates this neoliberal discourse around survivor responsibility. The women's declarations of resistance not only challenge dominant discourses that paint them as "vulnerable victims", but they also challenge Stevenson and Allen's modernist conception of self-love through acknowledging the fact that it can be difficult to identify the positive aspects of themselves due to the systems of oppression they experience every day. The kind of self-love that the women shared more aligns with Sonya Renee Taylor's (2018) concept, "radical self- 
love", which involves the deconstruction of toxic ideologies and discourses about women and survivors. All three women have identified these oppressive discourses, the ways in which these discourses have harmed them, and the challenges of consistent self-love due to this harm; yet, they continuously refuse to accept these dominant messages about themselves by identifying the love they have for themselves to move forward.

"By not making it about me." This theme is related to "radical self-love" and emerged through my interviews with Madison and Lisa when I had asked them how they had challenged their experiences of abuse. Madison's initial response was short, yet incredibly powerful. She responded, "I'm just...strong. That's the word. I don't label myself as the victim." This suggested that her strength allowed her to contextualize and externalize the violence she had experienced, which created opportunities to unpack the "victim blaming" discourses that are so prevalent in systems that are intended to support those experiencing violence. Madison spoke about CAS as a major contributor to the social construction of both victim-blaming and motherblaming:

How have I challenged my experiences? By not making it about me. I was labelled the victim my whole life. Like, I'm a victim of child abuse, domestic violence. I'm always the victim. Changing my framework, like my outlook. Even going back, it took years after CAS was involved and how she was blaming me for the violence that happened with baby daddy, my son's father, for me to be like, 'Hey, he was the problem. CAS decided not to address that problem but to blame me for being in that problem.' I never saw that. I legit never saw that as a problem. I thought it was me. CAS had the right to take my child away because I stayed in that relationship. (I thought) I did this to myself. But to be like, 'Hey, no...baby daddy was home.' She never spoke to him once. She 
never addressed the abuse. No, it was just me, me, me...How did CAS know I didn't stay in the relationship so that dad wouldn't kill my child? They don't ask that.

Lisa also discussed her strength, but in a way that endorsed her leadership, as well as externalize the violence, recognizing that she is a survivor. She said,

I feel like my experience has shaped me into being a good leader; to face challenges and not sort of fall apart even though everyone is telling you you're crazy, you're stupid, you're ugly, you're this... and then you start believing it and internalize it. I refused to internalize it even though I had nothing at the time when those things were happening. I had nothing to my name. I literally was broke and living in a shelter. All those things people were telling me, I was like, 'No, that's not true. I'm not those things. I'm brilliant, I'm amazing, and I'm a survivor. They're the problem, not me.'

A central element of post-structural feminism is its contextual analysis, which allows us to externalize gender-based violence and conceptualize it as a result of external factors rather than individual failures (Cannon et al., 2015; Morley \& Mcfarlane, 2012; Pierce, 2010). Madison and Lisa's visual narratives directly display the external factors, such as the dominant narratives of mother-blaming and victim-blaming (Ajandi, 2011; Mandel, 2010; Pajak et al., 2014) that have constructed them as the source of their challenges for remaining in abusive relationships. They actively disrupt these labels through contextualizing their experiences and identifying sexist biases, such as the fact that their abusers are absent from discussion and assessment (Humphreys \& Absler, 2011; Jackson \& Manix, 2004).

"I resisted by trying to play their game." The third theme that was magnified through the women's visual narratives involved more subtle forms of resistance that resembled silence and/or "conformity", or what Lisa called a "game". This form of resistance was demonstrated 
towards service providers, such as Children's Aid Society (CAS) specifically, as well as towards the women's aggressors. Lisa shared, "I resisted CAS by trying to play their game in terms of doing whatever they told me to do, as much as I hated it, and just keeping my mouth shut even though I had so much rage; just being quiet and doing whatever they told me.” Madison also spoke about this form of resistance but provided the reason for doing this: "I conformed to everything CAS told me to do. I remember if I didn't, they said they didn't trust my judgment and they would have to take my child away." She also discussed how she covertly resisted what CAS told her to do: "I have resisted CAS a lot, but behind their back. Haha. So, they asked me, I'm like 'yah I did that', but I didn't. Like I put a crib in, because CAS did not want me to co-sleep, but did my son ever sleep in the crib? Nope."

Lisa shared that she utilized a similar approach prior to her planned Family Court case involving her abuser. She said,

I went to court and just resisted again. I just kept my head down and did what I needed to do, and when I had the cards in my hand, I went after him. I always said, 'Okay, well the time is not right yet', and then finally the time became right. I always knew I would get my vengeance. I always knew I would get my vengeance, but I just needed the time and planned strategy.

She also shared that she continues to use her doctorate degree as a statement of resistance towards her abuser when he picks up and drops off her kids: "It's hanging on my wall with my many qualifications. I kind of put it there too because when he drops the girls off, he kind of opens the door and he can see it. It's kind of like a statement: 'You didn't stop me. What's on your wall?"” The statement says so much without actually saying anything at all. The significance of this strategy is heightened especially given the fact that her abuser consistently 
put her down, called her names, and told her she could never be a teacher. A similar resistance strategy was also found in Destiny's visual narrative. She shared that she was able to identify her father as a factor that consistently impedes her ability to move forward in her life and, therefore, she avoids telling him things. She provided an example of this in the interview: "I've never invited my father to a graduation because he's just gotten in the way of my progress. He's gotten in the way of me being the person I needed to be."

These reflections exhibit remarkable strength, power, and patience, especially when additional violence is experienced systemically. My review of the literature explored silence and refusal to inform as strategies (Bhattacharya, 2009), which can be seen in Destiny and Lisa's visual narratives; however, the review did not identify conformity as a strategy of resistance. Thus, the women's visual narratives disrupted my own perceptions and meanings of 'resistance'. In Madison and Lisa's excerpts, conformity seemed to be used to counteract the consequences of sexist, racist, and neoliberal responses to gendered violence, such as ongoing over-surveillance, or constant monitoring, of racialized women in child protection and social welfare services (Ajandi, 2011; Moffatt, 1999; Morrow et al., 2004). Lisa also used conformity as a tactic, but in a way that presented herself as remaining civil with her abuser prior to family court to "buy time" to plan her vengeance.

“I fought back." On the surface, this theme may appear to centre physical resistance as a strategy; however, none of the women's visual narratives actually discussed using physical resistance strategies. This finding contradicts existing scholarship that argues for "forceful" resistance tactics as the most 'effective' in the context of gendered violence (Edwards et al., 2014; Hollander \& Rodgers, 2014). In their visual narratives, Lisa and Madison spoke about "resisting out loud" or resistance through action, and how this made them feel strong and 
powerful. Lisa talked about how she remained civil with her aggressor and did what she could to "keep the peace" until she finished her doctorate. The reason for this is discussed further in the succeeding theme. Lisa recalled an incident shortly after completing her doctorate where she felt comfortable to vocally resist. Lisa's reflection of this was,

I remember a time when my flight was delayed a couple of hours and I asked my abuser and his mother if they could watch my daughters a couple of extra hours, and they said no and accused me of being a neglectful and irresponsible mother. I basically, for the first time, I fought back. I said, 'You know what? I look after these children; your son pays no child support. I've gone to school forever; I have a doctorate. I have a job. I have my own place. Your son lives in your basement and he doesn't have a car.' I told them I didn't want to talk to them. Even though my heart rate was racing, it made me feel empowered.

Lisa spoke about taking her abuser to court as her "ultimate form of resistance" because for years she had attempted to talk to and negotiate with him, but he refused to. She shared that the family court process was the avenue that helped her develop her voice and allowed her to overcome her fear of CAS taking away her daughters again. She said, "I did try to negotiate but when you're constantly being dismissed and being told you're crazy and you're not worth talking to, then you have to have a voice." Lisa talked further about her initial fear and how she overcame it when she said,

I knew he would use CAS against me, and I was worried that they would open up a case again and I didn't want everything I had worked for to go away. I don't trust CAS. I don't think CAS helps people. I think, if anything, it criminalizes people and it just pathologizes people. They didn't even take into consideration anything I had to say 
about what was happening. It's so disempowering to have everything taken away from you or being threatened to have things taken away from you and you've just worked hard to be a good parent and a good person. I guess I've gotten over the fear now. He can't take them away from me. At the end of the day, I just realized I'm a teacher, I'm educated, and I've never committed a crime, so what am I scared of?

Madison discussed her vocal resistance but at the organizational level in the context of subsidized housing. She shared that CAS had arrange subsidy housing up north, away from her friends and family: "I tried to resist out loud... I declined that subsidy and CAS got mad and they threatened and said I didn't make the right choice. I said that was going to make it worse because I would be so isolated up there. There's nothing up there. There's no transit, there's nothing. So, I said no.”

"Education is my armour." This theme is one that every woman cited through their visual narratives. They all spoke about education and its correlation with safety, but the meanings of education shifted based on their experiences. Lisa shared that attaining a formal education was a way of protecting herself and her family to ensure that she could take care of them. She said, "I find that my education is sort of my weapon, like my armour and it sort of shields myself and the girls." Lisa also briefly commented on the role education played in helping her recognize her experiences as violence rather than as a result of her 'failures'. She reflected on this when she said, "While I was pregnant, I spent time in the shelter and that was not a good experience... to me, it was really hard. It was degrading and I didn't understand why or how I had gotten myself there, but feminism and my education helped me realize that that's what society wants me to think. I didn't put myself in this position, other people did.” 
Madison's definition of education in this context involved self and experiential learning rather than formal education. Through her experiences of violence and her encounters with various services, she was able to educate herself about existing legislations and her human rights as they pertain to various systems, such as CAS, mental health, and the criminal justice system. She connected this to feelings safety,

Now I know to go out there and educate myself instead of just hearing what people are saying and taking it. So, that's another thing that I did myself. To learn to educate myself cus I didn't have that back then. And that all plays a part to safety. With all these components, I feel safe with who I am because I have that, and I feel safe and even a competent mother.

It is evident through these reflections that Madison feels confident in her knowledge of existing policies and legislations, as well as her ability to advocate for herself because of this knowledge.

In my interview with Destiny, she continuously spoke about the importance of her grandmother's teachings, as they have shaped her into the strong woman she is today. She reflected on her father's violence towards her and how it impacted her sense of self, but through her grandmother's teachings, she was able to feel independent and appreciate and understand her beauty. She commented,

She's teaching me to be this boss ass bitch, really. She's teaching me to take control of my own life. I was done judging myself and the matriarch showed me to be accepting and persevere and to be stoic, and to be true to you. I now don't feel like I have to please anybody. Now, it's like, 'No, motherfucker!' I've learned how to protect myself. Every 
girl in this family has such a strong head on their shoulders. It's just incredible. We could really rule an empire. We can.

Destiny only talked about her formal schooling when it came to self-reflection: "I was given the opportunity in school to learn how to open myself up and not spill everywhere."

The women's embodied declarations of resistance illustrate how education, particularly feminist education, was used as a strategy of resistance, resilience, and strength. This is interesting because the research I found did not discuss education as a strategy but was something I have used in my own experiences of violence; feminist theory and education saved my life because it not only provided me with a wealth of knowledge about the systems of power that work against me (Lee, 2008), but also provided me with a sense of community and support. While the education that all of the women received provided them with a similar understanding of their experiences, Destiny and Madison's passages in particular challenge Western notions of education and leads us to question, "What is considered knowledge?" Post-structural feminism criticizes objectivity and formality as the only sources of knowledge and truth. Rather, experiential and reflexive learning operate as powerful sources of knowledge, signifying that multiple knowledges and truths co-exist (Lu \& Yuen, 2012; McArdle et al., 2013; Vacchelli \& Peyrefitte, 2018).

"Supporting other people gave me passion". The sixth theme that was consistent throughout the women's visual narratives was around social justice and advocacy. All three women discussed how their experiences led them to careers that involve advocacy against oppression through policy analysis and research, critical self-reflection, and peer support work. Madison directly commented on this when she said, "It's hard, but it's developed into a passion where I don't want to see this happen to other people, and that's the resilience and strength to 
overcome this past and make it something." Lisa spoke about the strength she feels when she writes and delivers presentations about policy because her work is developed with the purpose of creating systemic change. She highlighted that she will be presenting her recent research at the Canadian Sociological Association in British Columbia in spring 2019, which aims to reveal how children become acting agents in their communities and that, despite what many people think, they are not "too young" to think about race relations. She reflected on a time when her eldest daughter said, “I don't like that my skin's darker than (my younger sister)". Lisa spoke about how this inspired her most recent work: "I just wanted to unpack that. I had to unpack that with her and that really got me interested in this topic. Like, where is this coming from? Already the ideas that kids have about things. We need to have these conversations."

In sharing their embodied declarations, all of the women recognized that their experiences are unique and, therefore, differ from other survivors based on the subject positions in which they occupy. Destiny noted that through working in the field of social work and through ongoing self-reflection, she was able to identify her privilege in ways that allowed her to witness the many other forms of social and political injustice that are so pervasive in society and, in turn, provided her with further passion to help others. Madison also spoke about this. She commented, "It's important to understand the system and to understand that it's not the same for everybody. My experiences are different from everyone else, but to know what the system can do to you to basically oppress and further marginalize you." Madison continued to talk about the ways in which her experiences and critical reflection have positively impacted her peer support work. Specifically, she talked about her negative experiences with service providers and how she was able to use this to learn what not to do in her work with clients, 
“...like how they (service providers) speak to you and how they are very demanding, right? So, when I speak to clients or participants, it's that self-determination. I want to hear them."

The women's commitment to social justice and advocacy provided them with the space required to reflect on their experiences of violence, as well as contribute to local activism in various ways and in various settings (Ajandi, 2011), which challenges dominant ideas about what social activism looks like. Social activism does not necessarily need to involve protests but can simply be reflecting on one's positionalities and the implications of this in their work. Whether through policy and research, reflection, and/or peer support work, all of these women are engaged in dialogues that resist multiple forms of discrimination and oppression and validate the many different ways of knowing and being (Ajandi, 2011; Cannon et al., 2015; Pierce, 2012; Morley \& Macfarlane, 2012).

Family as "my lifeline". Another theme that emerged from the interviews was family support. Each woman pointed to particular family members who provided them with strength, safety, and purpose. This theme was central to Destiny's visual narrative but was specific to the women in her family: "My grandmother is our lifeline. It's the women who have saved me. They all had a contribution from removing me from that danger and reminding me of my strength, reminding me of my skills, reminding me that I have a safe space and that I have several safe spaces." I found this to be extremely powerful because it unsettles this "Damsel in Distress" narrative that exists, especially in the media, that constructs women as dependent on men to be "rescued" from harm (Mura \& Mcmillin, 1996). As Destiny stated, it is the women in her family that have played an active role in 'saving' her from danger.

For both Madison and Lisa, their children offer them a sense of love and purpose that they had never experienced before. Madison shared that the love her and her son have is 
unexplainable and goes beyond words but is visible to others. This is demonstrated in the following excerpt:

The love my son and I have is the most amazing thing in the world, and no matter how mad I am at him, I still love him. I can't explain it. I care so much and that's what I learned what love was. Like, I didn't know what love looked like growing up, but I learned what love was through my son. I can radiate that to everyone now, even to strangers.

This love provided Madison with the strength to be the confident mother she believes herself to be. Lisa shared a similar reflection about her relationship with her daughters. Lisa said, "Before I had children, it took me 5 years to do my undergrad. I had no idea what I wanted to do, and I just didn't really have the drive. Once I learned I was pregnant though, I became motivated. They gave me life and they gave me purpose."

The literature review discussed social supports as a source of survivors' resistance, resilience, and/or strength because they challenge the abusers' control tactic to isolate their partners (Jacinto et al., 2010; Pyles \& DeChiro, 2012); however, the scholarship did not consider children as members of these caring communities, which assumes only adults have the capacity to adequately support survivors. While Destiny's visual narrative shows that the adult women in her family have provided her with safety and strength, Lisa and Madison have found safety, strength, and purpose in their children. The women's family support can be considered what Jacinto et al. (2010) call "community-based practices", which challenge neoliberalism and the increase in police-based responses that fail to support survivors (Johnson, 2017; Morrow et al., 2004). 
“Once I found God again, everything became safe." The final theme is one that the majority of women cited, which was around spirituality. Lisa and Madison spoke about the use of mindfulness as a coping strategy for surviving the violence itself and its impacts. Lisa talked about being outside with nature because it makes her feel calm and, thus, opens up possibilities to reflect on her strengths, allowing her to move forward for the next week. Madison discussed mindfulness as a tactic that she uses to remind herself that she no longer lives in the past, which makes her feel safe and protected. What I found interesting is that both women talked about how mindfulness creates space for gratitude for themselves and what they have. Lisa said, "It's (mindfulness) my therapy and appreciation for myself, and I know that there's nothing that he can do cus there's no way that he's going to take my kids away." Madison shared that mindfulness helps her "to just reflect. Not more reflection about where I came from, but reflection about gratitude. I have to be grateful for what I have...to appreciate and show gratitude; like, I have this now. I can now go outside and not have to dress up as somebody else because I'm scared somebody is going to follow me." This captured my attention because Jacinto et al. (2010) presented a similar finding where spirituality and social support provided opportunities to gain important insights and, in turn, facilitated self-love and self-compassion. This would be interesting to research further (p. 120).

Madison spoke about a very dark time in her life where she lost her purpose and her passion due to the violence she was experiencing, but when she heard a message from God, her life changed. She reflected,

I heard a message from God. I'm not joking. He said, "Why don't you take all of this pain and make it something?" So, I did take that and then applying that to what I am doing today in my life...I've always believed I had a guardian angel and the angels were 
there to guide me. It's just that during the bad times in my life, I couldn't see it through the darkness. Once I found God again, everything became safe. I felt safe. I felt peaceful.

These statements display the powerful role that spiritual and religious coping can play in offering support to survivors of gender-based violence, which is typically sidelined in existing resistance research in this context. For both of these women, spirituality and religion were used as sources of strength (Drumm et al., 2014; Jacinto et al., 2010). 


\section{CHAPTER 6. CONCLUSION}

In this research, I explored and presented survivors' embodied declarations of resistance, resilience, and strength within the context of violence against women through participant-generated photographs. The purpose of using photographs was to amplify alternative voices in creative ways to disrupt dominant discourses that construct survivors of violence as "vulnerable victims" in need of "saving." I explored the following question with three women: In what ways do survivors resist gender-based violence at both individual and systemic levels? As I collected and analyzed the data, I was continuously reminded of Christi Belcourt's (2017) central argument around photographic representations of action rather than "static" images to highlight the ways in which women actively challenge violence.

Through exploring my research question with the three women I had the pleasure of sitting down with, I was able to present their central photos that best represented their declarations of resistance, as well as the subsequent internal and external narratives of them. Through analyzing the women's visual narratives, I identified many consistent themes that speak to their declarations of resistance, which are discussed in detail in the findings and discussion section (Chapter 5). These themes included: (1) self-love, (2) contextualizing violence, (3) resistance through action, (4) education as protection, (5) deliberate silence and conformity, (6) social justice and advocacy, (7) family supports, and (8) spirituality.

As I have argued throughout this paper, solely focusing on survivors' oppression, discrimination, and victimization is dangerous. Ignoring their strategies of resistance can perpetuate violence and lead to misrepresentation and disempowerment because it supports gender stereotypes that construct women as passive, weak and vulnerable (Hollander, 2005). 
I want to emphasize the immediacy of addressing this issue, especially at the structural level. Lives are at stake. My research briefly illustrates the day-to-day impact of Eurocentric and patriarchal dominant discourses that 'victimize', violate, blame and shame survivors. Despite these labels, however, survivors continue to resist, even if it is just enough to stay alive. The embodied declarations featured highlight the women's power, strength, and resistance in a way that pushes boundaries and forces us to rethink what we know about gendered violence and the survivors that experience it.

Madison ended her interview with a powerful quote reminding people that victimblaming is dangerous: "I wanted to express the importance of not to victim blame...(survivors) themselves blame themselves and then they go off and blame other people...it's so entrenched in society that we can't even question the problems and how it's happening in the system. Like, how CAS is blaming me for being in the violent relationship and not blaming the father for being violent. Like, the abuser is violent. If my son is violent, I'm going to address his violence. I'm not going to blame it on the person he hurts. Like, how does that make any sense?' Lisa's words beautifully exhibit how shifting the discourse can create powerful change: "I never really thought about how powerful I am until today. It's hard to when there's so much crap being said about you. But looking at and reflecting on all of these pictures, I am reminded of my beauty, my wonderful life. I am reminded of what I have. I have so much power.” I now urge you, as the reader, to re-read my research question above and reflect on the ways in which your ideology, research, and/or practice have fallen short of the rights and needs of the women and girls in your lives. Reconceptualizing survivors as strong, resilient women will save lives. It saved mine. 


\section{APPENDIX A. PARTICIPANT PHOTOS}

\section{Madison}

Photo 1

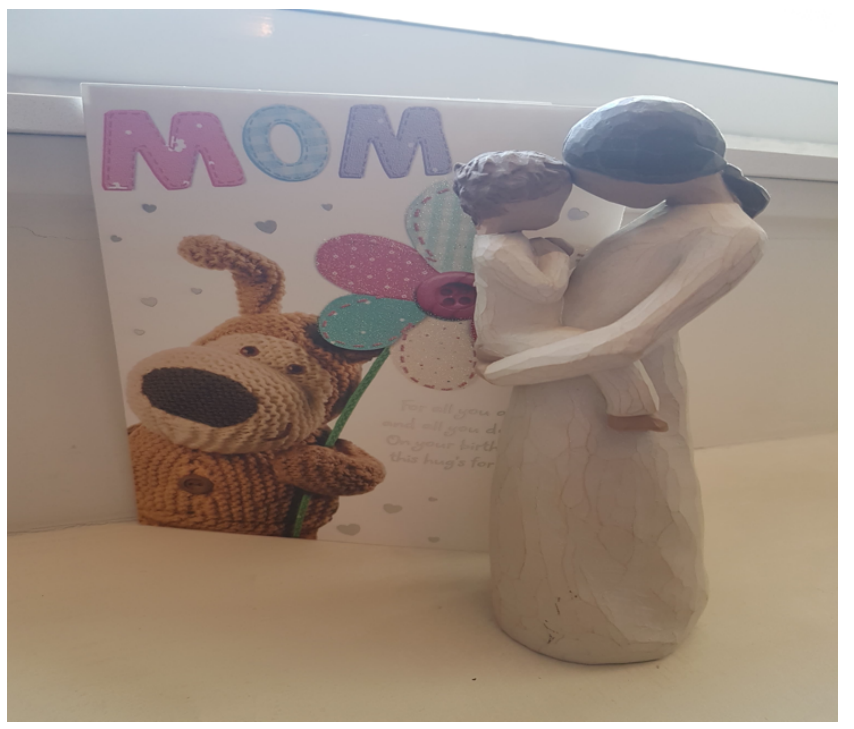

"My son gave me the card for my birthday and the statue represents me and my son and our bond. This picture demonstrates something I never thought I would ever be because of the loss in the past, I was a mother in the past... I lost that through violence. I never knew how it would look like to be mother now because of those past experiences, but through resilience and strength, um..I am who I am today. And I can have a child and be an okay mother, an excellent mother despite all the messages I've gotten from the past, the abuser in the past, even from my surroundings, even from service providers who doubted me, that I could ever be a mother, that I shouldn't be until I worked on myself...things like that. Ya...so I had different messages telling me this isn't for me, but I resisted. I decided to give birth. There's a lot of other options that I could have had not to be a mother, but I went through it. It's not that bad, it's the best thing that has ever happened to me."

"When I look at the statue, when you look at the statue, there is a bond between the mom and child. The way the mom's head is leaned towards the child's head. This is a bond I never had with my own mother. I don't know if it's more of a western sense of love in this demonstration because in my culture we don't hug or kiss, the mom doesn't do that. We show it in other ways, right? Whether it's through giving shelter or caring for us in our academic needs and things like that. But growing up in a very western society, I have always envisioned love looking like this, where mom comforts child, mom and child have a bond, a physical and emotional bond. And I can see this in this statue. And that's the bond I've always wanted and that's the bond I have with my child. And that's why I chose 
that statue. And when I look at it, it reminds me of everything that my mom and I did not have in terms of the physical affection, the hugging and kissing... and even having conversations with my mom on very personal things. We don't talk about that in my culture, we keep everything inside usually from what I know. So, it's very different with him and that's what makes our relationship so strong. To have someone to talk to...even back in the days when I was going through violence, if I had my mom to talk to I think things would have looked a lot different. I would have had a lot more support. So I want to make sure my son grows up knowing that he has someone to talk to, and someone who is not judgmental and who is by his side no matter what."

Photo 2

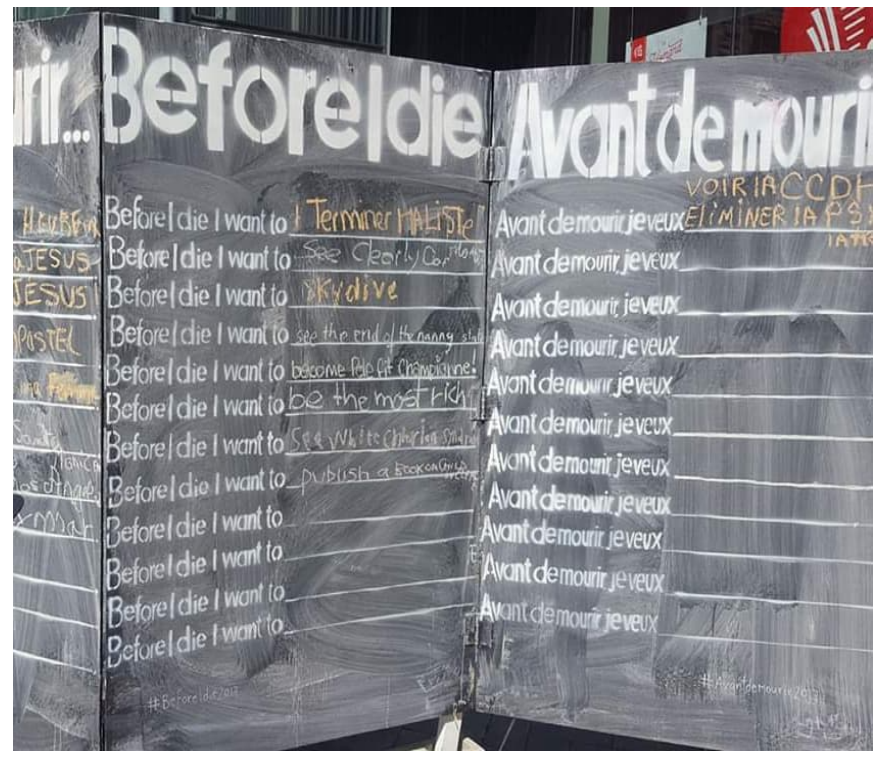

"I was in Montreal with my family. My son was actually in this picture, but I cut him out. He wrote something somewhere. But um ...this photo they were doing a project in different cities, called "Before I Die", which made me sit there and look at the board and consider what I wanted to do before I died. And I realized what I wanted to do, and what my passion is. It's for early intervention for child maltreatment, so it doesn't happen. So, to work with children. Um... and that's through all the experiences I've had. Like, I realize this picture means to me all the experiences I've had in the past, all the child abuse and domestic violence, and everything stems from how I was raised as a child. And then my passion became how do I support others to not go through what I did as a child, which I learned which is why I probably stayed in a very violent relationship for so long because of who I was; I was very compliant. I never spoke up. Yah, I was very compliant. I only saw the best of the world. There can't be mean and evil, even though I grew up in a very violent home. So, this picture represents everything I am today, the shift of my passion, why I wake up every day to do what I do in life, is to support children and their families." 
"I'm still alive today and I still have passion. I never had passion. To be honest, back in the days when the most extreme violence happened through domestic gender-based violence, which was over 15 years ago, I had no passion for anything for a very long time. I just wanted to die; I just wanted the pain to end. But, today when I look at what I'm doing with my life, it's because of these experience of my past, because of the gender-based violence, because of the child abuse where I have the passion to do what I'm doing today, which you know, I don't give up. It's hard, but it's developed into a passion where I don't want to see this happen to other people. And that's how the resilience and strength to overcome this past and make it something. All these experiences, I've made it something. Even my past job as a peer support worker, I used it to make it something to support other people despite how scary it was and how it just wasn't good."

Photo 3

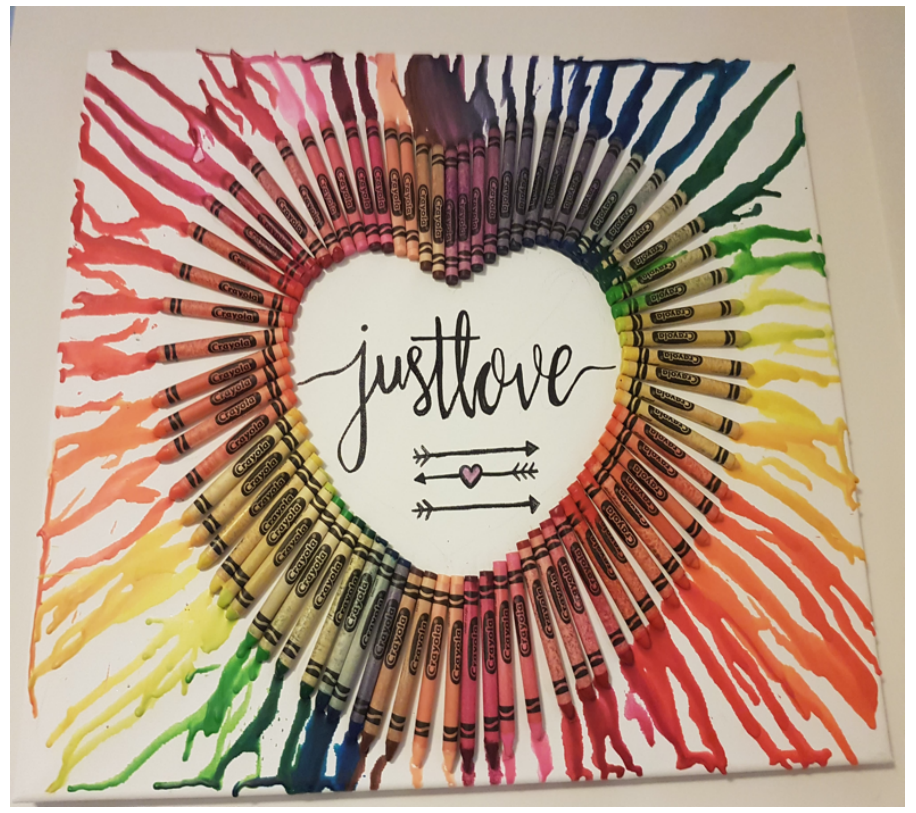

"This is a canvas of a heart, crayons. I think it's the rainbow colours, I had to Google what the order was. My son and I made this on his day off. He was sick, so we decided to do an art piece because we saw a similar one, ours is better though [laughs], a similar one at the doctor's office. I used a hair dryer in different angles so that the crayons would melt, and they just dripped to the sides. It's like exploding with love. But there's still pain, but there's still love because, let's be realistic, when there is love there is still pain." 
"That's why it says 'Just Love', to do everything with love. And that is and was, like right now I'm having a hard time, but love was that staple, that key foundation. As a parent that struggled through gendered violence and child abuse, that kept me ummm strong and resilient, to keep moving forward, right? So, this picture with the dripping of the colours and the layout of that is to be as inclusive of everything as possible. That's why every crayon in the box was used. And the dripping, like I said, represents the love radiating out as well as pain too."

Photo 4

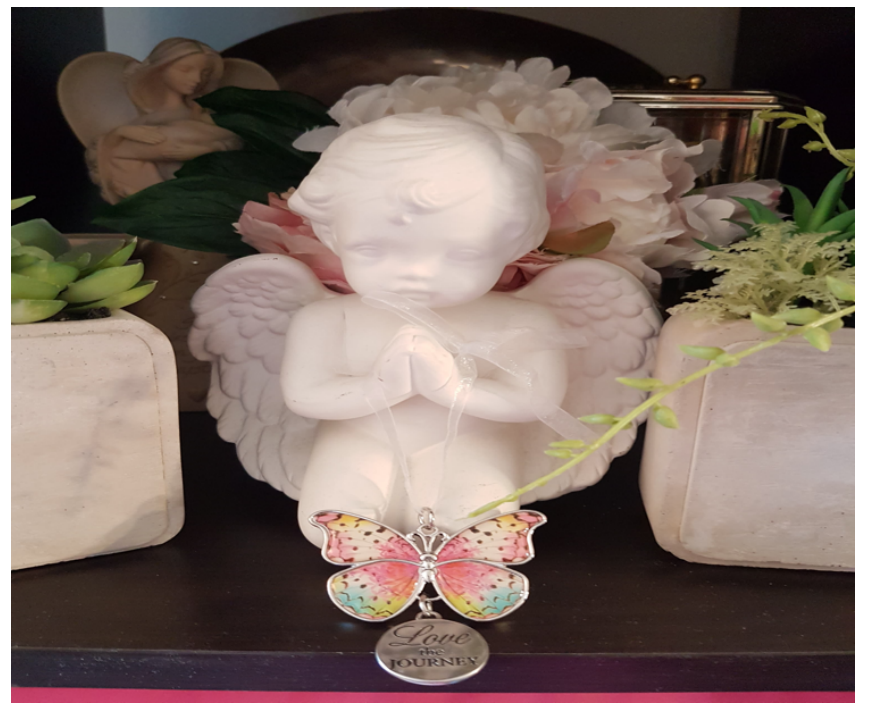

"There's forever flowers everywhere with an angel. It says, 'love is a journey' because love is important. There are so many things in my place that say, 'love'. There's an angel in the background. It represents safety. To me, when I look at it, it's safety. The place I have now, I finally feel safe in my life. I actually thought about this after I took the picture, umm ...that I never really had safety in my whole life. And to be in my apartment now, I've never felt so safe, both physically, like I'm not running for my life. I'm not scared someone's going to break in, or that someone's going to kill me. I can leave the doors unlocked. Sometimes I forget to lock the door and that's okay. Like, I don't have that vigilance anymore. Or even walking outside, I'm not scared someone is going to jump me, and that was a concern my whole life. So, that's the physical space safety. And then I'm very appreciative that I have a home that I'm not afraid to go to. I don't have to put 50 locks on the door because someone might come in and break in. And um ... emotional safety. I'm not afraid that I might have to hurt myself or I might have to die or suicide or die by suicide. And that was real in my past. Any little thing that I perceived as overbearing or painful. So, that's why this picture, where it is in my place, represents safety. 
(The angel represents safety) cus God is guiding me the whole time. A few years back, I actually went to do bible study because I lost my way. It was a very dark place in my life. The dark place lasted a very long time, but up to the dark place in my life, I found God again. And then, maybe three years later that's when I heard, 'Use your experience, do your passion', right? So, I've always believed I had a guardian angel and the angels were there to guide me. It's just that during the bad times in my life, I couldn't see it through the darkness. Once I found God again, everything became safe. I felt safe. I felt peaceful. I knew God would guide me through everything in the end and that's how spirituality played a big piece in where I am today; the strength, resilience, and resistance because I can trust. I can take the risk. In the end, God is there for me."

\section{Lisa}

Photo 1

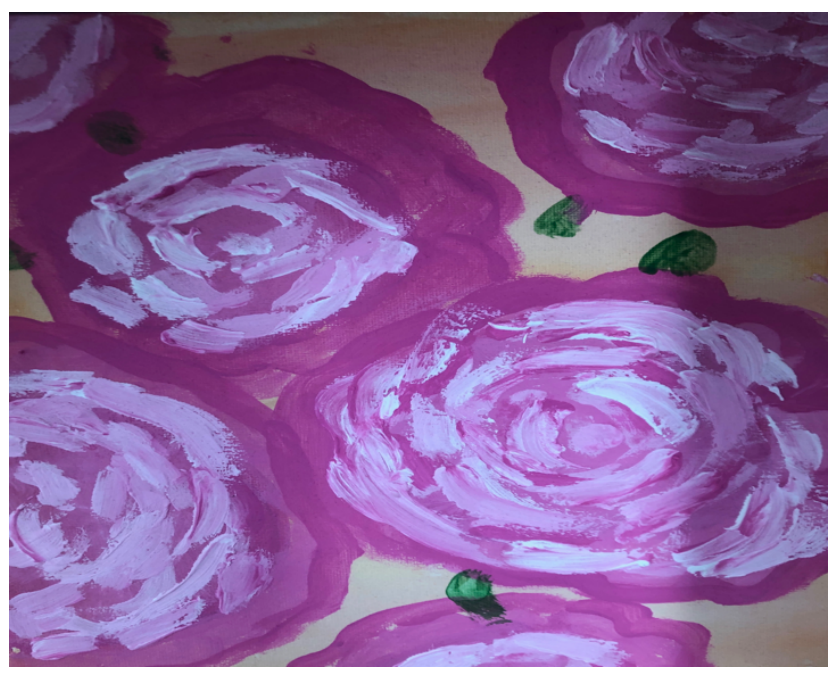

"This is a painting by my older daughter of pink roses. This photo was given to me on Mother's Day and, to me, it represents blossoming and it represents sort of a flourishing and love for my older daughter and I. I think the flowers represent like when things die and usually when things are hard and we think that there's no growth in life or we're stuck, the flowers represent sort of a growth, getting past, and a renewal; a rebirth. For me, it's starting fresh. Especially coming from my older daughter who's very much like me and very competitive and determined. It shows that she is a sense of inspiration for me. It shows that every year, you start over with new flowers. Every year you can bloom again." 
Photo 2

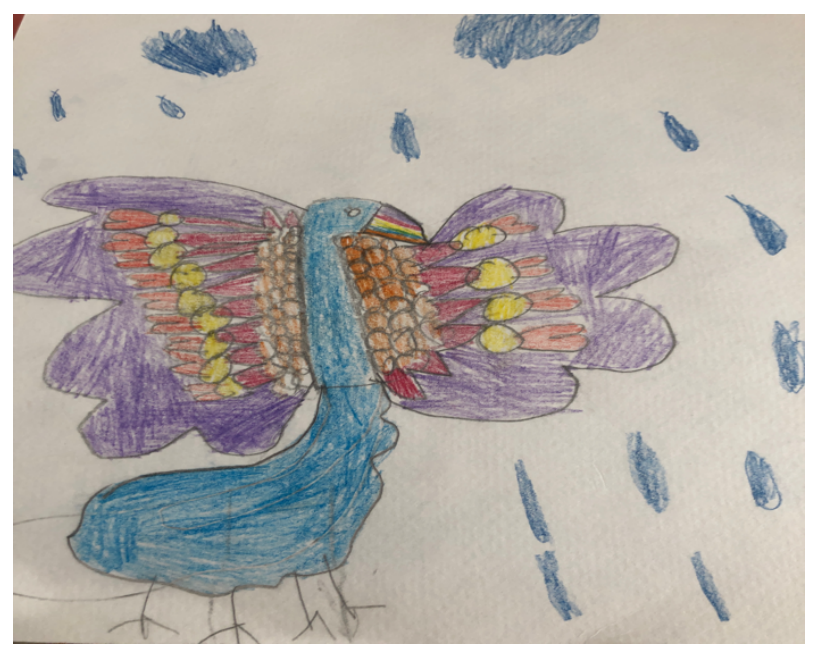

"This is a photo that my younger daughter drew of a peacock. It's interesting that it's in the rain because it really reminds me of perseverance; that even though it's raining outside and there's dark clouds above, the peacock is still out with its bright colours and it is still going. It just shows that, you know, it's not sunny, there isn't anything sort of beautiful happening in the background but rain and dark clouds, yet the peacock is still holding it's head up and it's feather are out in full colour, and it's going regardless."

"This really makes me think about going through what I went through with their dad and having him try to take my children away, so like things were very dark, but I didn't give up and I kept myself going, you know? I didn't let him dictate my life. I was living with him and we had an argument and his mom called the police on me, and CAS got involved. They took my children from me for a time, and it reminds me of when I was pregnant with my youngest daughter and his mom said I would never see her. I was so sick I couldn't even leave the house, but I got on a bus and I went to (a college) and enrolled in Early Childhood Education. I started classes two weeks after while I was pregnant with (my youngest), so that I could go to teacher's college. I was seven months pregnant." 
Photo 3

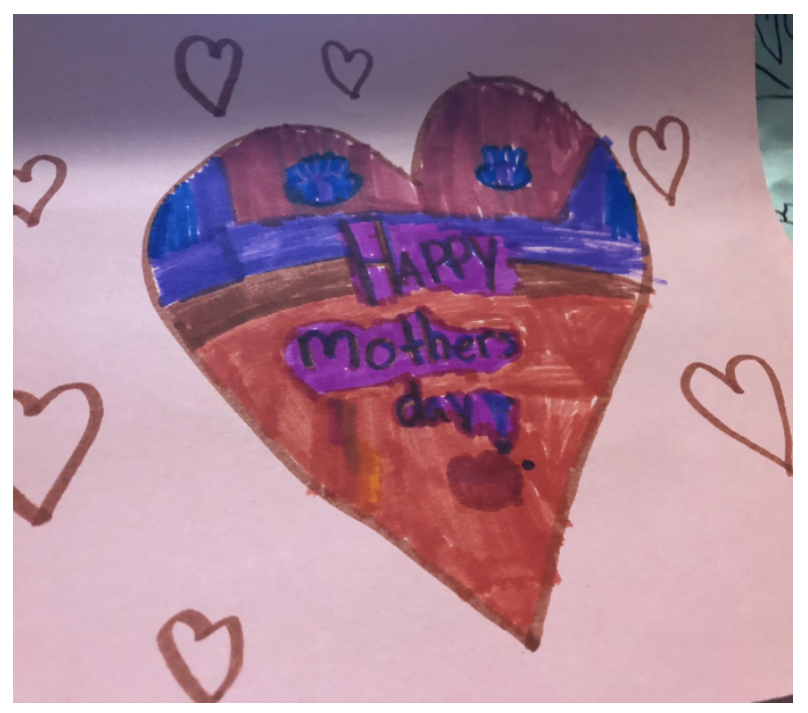

"Photo number three is a Mother's Day card made by both of my children that represents the strength of our bond, the three of us as mother and daughters and the closeness of our relationship. The sweet things that they wrote in the card how I'm the best mom and that they love me. Everything in it just sort of goes to show that even when people are saying all kinds of horrible things about you, actions speak louder than words. Their father and his mother basically will say that I'm not a good mother, that I'm an unfit mother, and that I'm like an unstable mother. I'm constantly feeling like I'm under surveillance for something I haven't done and having to constantly prove things. But my children have an endless supply of memories of the three of us together doing lots of fun things. No matter what outside voices say, it's an unbreakable bond."

"I kind of feel like (my eldest) is very much like a mother to me. She will tell me, 'You don't need makeup; you're beautiful!" 
Photo 4

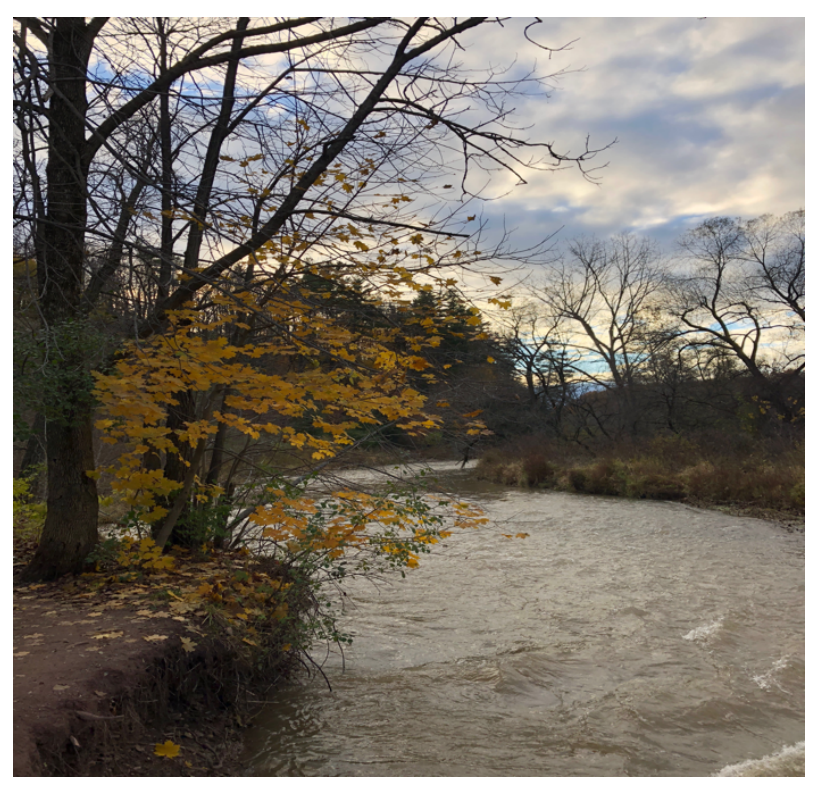

"Picture number four is a valley. I park my car and I have to go down a big hill. It's a hiking trail. When you get down to the valley, there's a big river. I usually go there once a week on Sunday's when I'm home. I used to go here when I was a kid and my dad used to take me here. At a young age, we used to go there all the time and put rain boots on and go in the water. So, I think that's where I got a love of nature. I spent a lot of time here before I went to court with my abuser. It's just a grounding place and it's very calming and a good place to put everything into perspective outside of the day-to-day busyness of life. Some people say going for a walk in nature is basically a therapy, so I find this to be much more beneficial than any other kind of therapy I've ever had because by the time I'm done, my endorphins are up and everything is much better and much more energized. I love the fresh air. 


\section{Destiny}

Photo 1

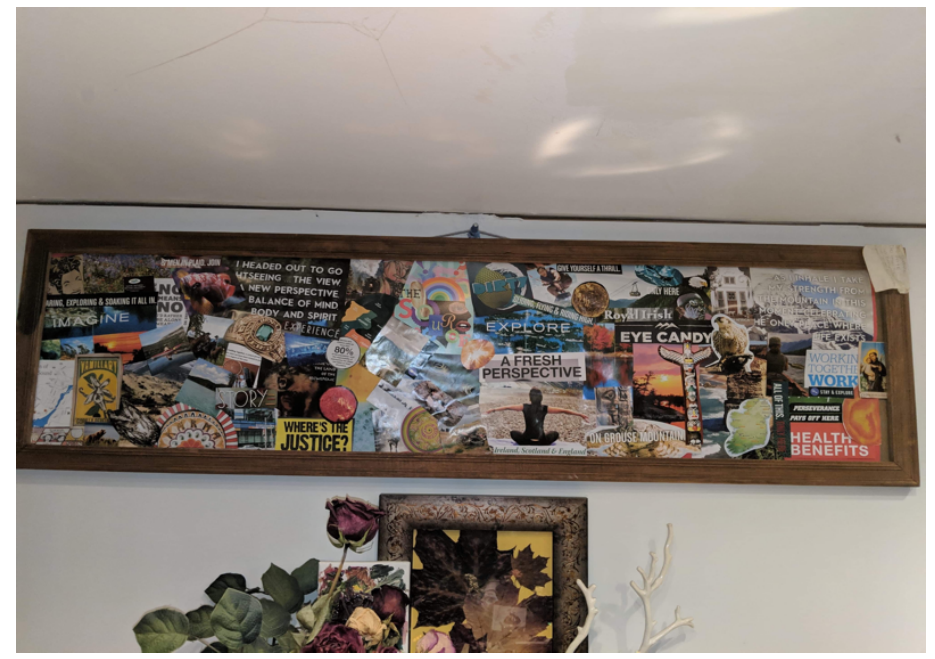

"The first photo is a collage that I have in my room. I built this collage out of my aunt who passed, her mirror. I just removed the mirror, and outside is the wooden frame. The kind of photos that I have are cut and pasted here and they have some similar themes going on; a lot of natural activities, some of the photos I have here are titles of "fresh perspective", "explore", "where's the justice?" To me, I find a lot of my strength comes from my environment, in the natural environment that I'm in and that I wish to be in, so I have a lot of imagery of large landscapes and water and mountains. My goal for this was to create it with a friend, and it's ironic how this friend actually caused a lot of harm. So, I actually ended up doing this on my own. For me, this represents my resilience because I've been told at a young age to envision what I want. I was told not to envision what I don't want, but what I do want. I was exposed to other collages that kind of mimicked "the secret", and I don't know if you've heard about that, but it's about the power of our minds and intent. I was struggling a lot at the time that I built this. I needed something fresh to look at. In a lot of ways, this collage is what I wanted to be like almost.

Throughout the 5 years that I've had this, I'm going in a direction that I can actually see in this collage. There are actually some things that have happened and have occurred, like getting into social work. At the time, I wasn't in social work. So, this collage kind of represents what I wanted to be, the strength that I wanted to have, or really the strength that I did have and it took for me to see the exterior before the interior."

"I felt how important it was that it was built in my aunt's mirror. I have a strong lineage of strong women in my family and I like that she's the border to this chaos that I have here. It's almost like the protecting layer, the frame in which I can go out into the world. I can be free, I can fight myself, but I'm always protected."

"This collage is very important to me. It does represent resilience and looking back on it, 
I see how resilient I was, how much I was actually craving and wanting to be, how much I wanted to grow and not just survive. Now when I look at it, I see accomplishment. I've seen a lot of the landscapes that I have here. I have this person right in front of this image kind of facing the water, back to us with arms wide open, and that's kind of where I am, with a "fresh perspective". It represents my willingness to want to survive, my willingness to find the things that are going to help me grow and protect myself. I love my collage."

Photo 2

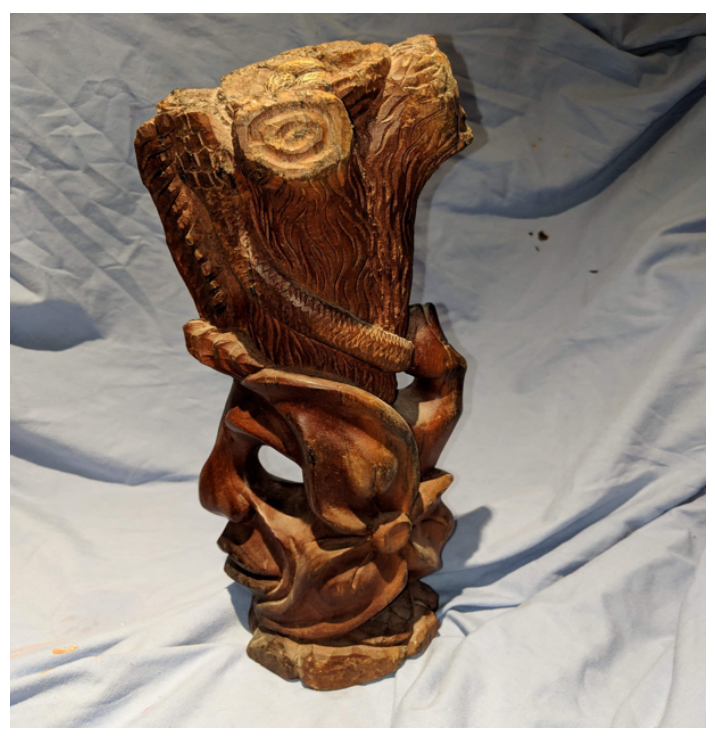

"The second image is a wooden sculpture that I picked up in Cuba. Only a few a years later have I started to really understand why I picked this random sculpture and started to figure out these small little details that I haven't seen... I never really understood why I chose this. I thought, you know, that the woman underneath was beautiful and even the nest on top I thought was interesting. But I really liked the woman and how beautiful the flower looked. Slowly but surely, this has just been another physical representation of my foundation. The women in my family are just such a strong, stoic, lineage of spirits that really do persevere and break through the mold. And I like that at the stump of this work, there is the woman there and that she's the foundation. It does represent my life through all of the challenges that I've experienced and the gals in my family have experienced. There's always been a woman to cradle that fall to make sure we were safe, and we had the skills and we had the protection to do and to be who we wanted to be."

"We have this beautiful flower that kind of represents the soft femininity, but I also like this thumb that's pinching down the snake that's crawling up to the nest. I think of the nest as my brothers, as myself. I grew up with 2 of my cousins and it was always us three for 20 years, and then our siblings kind of came back into our lives. But it's this snake that's going up to this nest that's being pinched by this woman is just such a beautiful representation of the men in our lives, you know? This snake is very much a part of this trunk. It's carved right into it and I think that's so important because 
without these men, without this counterpart, without the other half, we wouldn't be us. I'm grateful and thankful for that, but what I'm most grateful for is that pinch right there. It's that prevention and the resistance. Our fathers were very much trying to take that away. If it was up to him and that thumb wasn't there, he would engulf us. I love that even though she's still pinching it down, it still has its presence there. It still is quite close, and she can't prevent all of the harm that could happen, but creating that safe foundation, creating that extra, 'Don't touch my girls', is beautiful because that's in my grandmother, my aunts, my mother, my cousins.

Photo 3

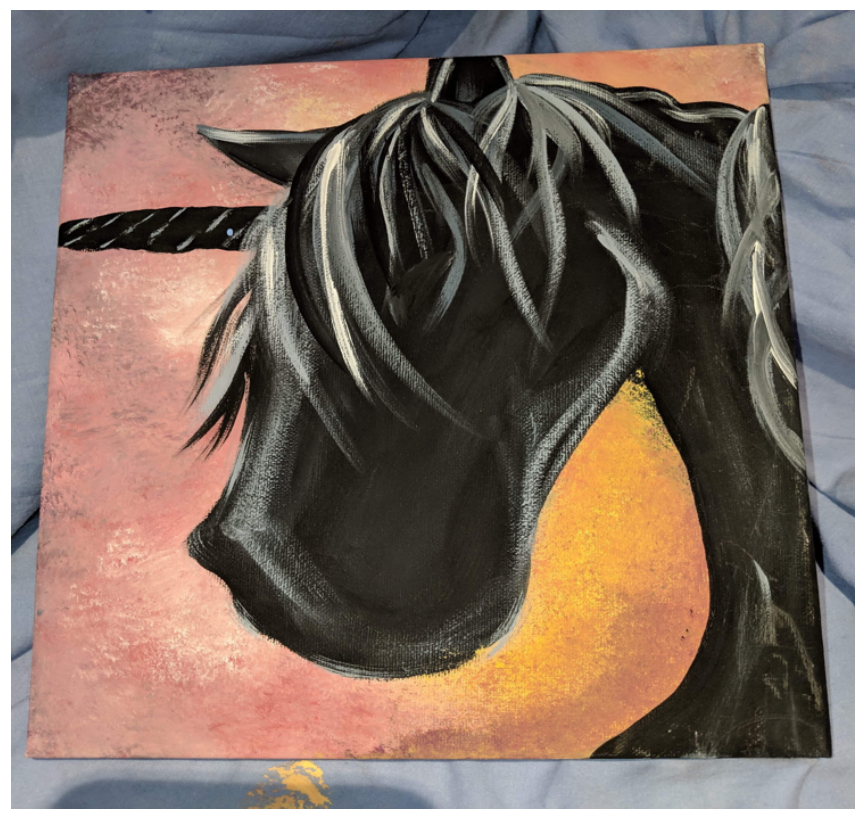

"For me, this was one of the first paintings I had done getting back into my hobbies. When I was really young, I was really, really artistic, and I was kind of given the tools to grow and I was struggling at that time with stability and a concreate schedule cus my parents always worked and were in the care of our grandparents, aunts and uncles. I lost touch with a lot of habits that I should have developed. Like, my reading habits, my studying habits, and my artistic skills and all in the name of survival."

"We talked about some of the ways that gendered violence is involved in families and family trauma, family violence. My family, especially my father's side, there is so much toxicity. This dark horse, it was me. It was me. I say 'was' me and I'll explain why. I always felt I was not good enough, that I was not the one who was going to fit in...I never really understood that. I just remembered it."

"This dark horse solely has to do with that paternal side. I say 'was' me because this ended up being a reflection of them. I shed the label of this negative dark horse and that family, and I started owning this unicorn, like I am the special one in that family. I 
found out when my grandmother was sick and when she passed, that she held onto a lot of information that caused her children, my aunts, my uncles, and my dad, to be the people that they were. And for all these years, I internalized their behavior. I internalized how they treated me, and now I understand why. My grandfather used to molest my aunts. And my grandmother knew, and she did nothing about it. My grandmother always worked on protecting her exterior, protecting her image to her community."

I remember my aunt growing up. I used to feel dirty cus I would have these chocolate stains and my hands smelled and she used to always make me go wash them, and nothing was ever clean enough. And I thought I was dirty the one, but really I was talking to her and she goes, "(Destiny), no. I am so sorry." This is the first time I ever heard an apology from when my grandmother was passing. She goes, "I was the one who felt dirty." These are all dark secrets that they're ashamed of and I'm thinking oh my god, like, I'm so proud of my aunt. I'm so proud of her. It was a cathartic moment. It was a full circle and finally made sense. It's not me! She didn't even know she was validating. She was just telling her story. This horse to me, I took it back. I took that label back. I used to think black sheep, you know, I was the black sheep nobody wanted; kind of just hanging around hoping for some validation, and now it's like I literally am the only truth in that family. I'm the only person who recognized my trauma, recognized where I've gone wrong, recognized how my lineage played a factor in that, and recognizing that I had that family violence and connecting that to myself. I was able to shift that blame."

Photo 4

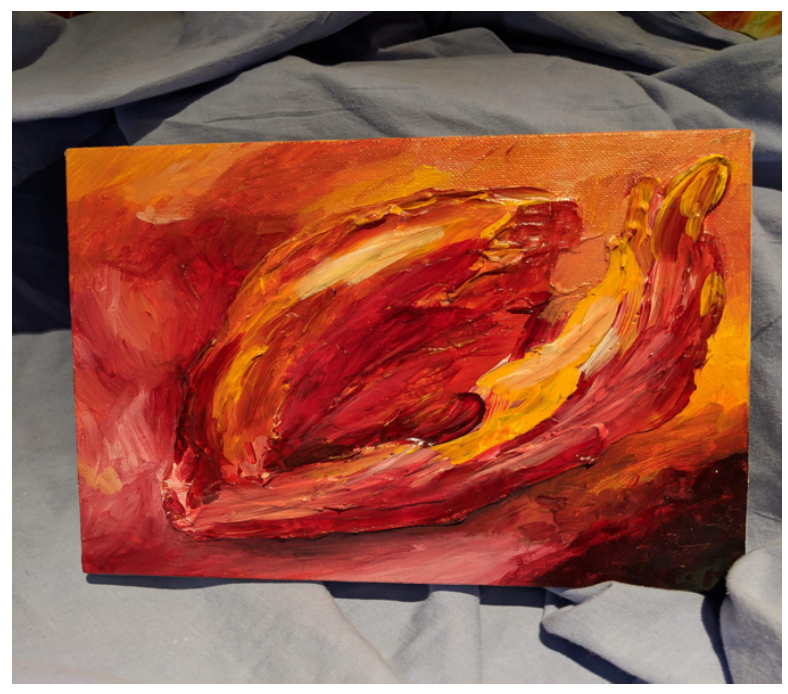

"This is a very texturized oil painting done from one of my great gal friends. I bought this image at one of her exhibitions. It is a twelve by twelve image abstract image of women genitalia; a vagina. It's abstract." 
"My declaration of resistance is me being proud to be a woman. I felt like my dad made his image so shiny and so charming and so beautiful, and he put down the women so much in my life. It got to a point where I wasn't listening to my grandmother. I was pulling away from my mom. Kids should not have to see women being thrown into walls or see six women in one night. It was very toxic. So, I was really shifting away from this matriarch and it wasn't until college, when I was really dissecting. Like, what's going on? What is making this nasty man look so attractive? What is making his characteristics that are so damaging and self-sabotaging, what's making that look so great? I was figuring it out. I realized how much we do internalize. I was figuring out that my mom had battered woman syndrome and that I had battered woman syndrome. I was emotionally and physically, and mentally restrained. I was his. And now knowing about my family history, it makes sense. This vagina is so precious to me, you have no idea. This vagina is so important to me because every woman in my family has had a contribution to saving me from that life." 


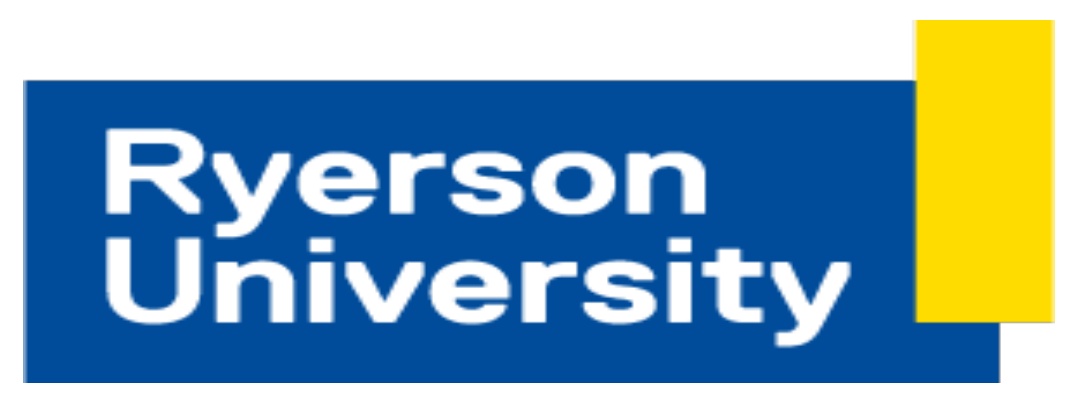

\section{Consent Agreement}

You are being invited to participate in a research study. Please read this consent form so that you understand what your participation will involve. Before you consent to participate, please ask any questions to be sure you understand what your participation will involve.

\section{GENDER-BASED VIOLENCE AGAINST WOMEN: STORIES OF RESISTANCE, RESILIENCE, AND STRENGTH THROUGH PHOTOGRAPHY}

\section{INVESTIGATORS:}

This research study is being conducted by Nicole Fontyn, supervised by Dr. Samantha Wehbi, from the School of Social Work, at Ryerson university.

If you have any questions or concerns about the research, please feel free to contact Nicole Fontyn at nicole.fontyn@ryerson.ca or Samantha Wehbi at swehbi@,ryerson.ca.

\section{PURPOSE OF THE STUDY:}

This study is designed to explore the stories of resistance, resilience, and strength amongst survivors of gender-based violence. For this study, gender-based violence against women is defined as any form of violence (physical, emotional, verbal, psychological, financial, sexual, and/or systemic) perpetrated against women.

The study will interview 3-4 participants. Participants will identify as women, have previous lived experience of gendered violence, and be at least 18 years of age. Participants must currently live in the Greater Toronto Area. This study is being completed by a graduate student as requirement for completion of their degree.

\section{WHAT YOU WILL BE ASKED TO DO:}

If you volunteer to participate in this study, you will be asked to do the following things: 


\section{Photos}

- You will be asked to take photos with a camera of your choice (e.g. phone, digital camera, professional camera, disposable camera, etc.). If a camera is not available to you, you will be provided with a disposable camera at no cost. These photos should represent your story of resistance, resilience, and/or strength as it pertains to your experiences with gender-based violence. Please be advised that these photos can include anything of your choice (e.g. objects, places, artwork, etc.); however, please avoid taking photographs of people or anything specific that may accidentally identify yourself or others (e.g. personal tattoos, items of clothing, piercings, places of employment, etc.) due to confidentiality reasons.

- If you are not using a disposable camera, you will be asked to share 5 of your favourite photos with the researcher. The researcher will send you a Dropbox file request, which will ask you to upload your photos by clicking a link to the Dropbox file upload. Please note that you do not need to have a Dropbox account to share these photos, and that only the researcher will have access to your photos. Feel free to assign filters and make edits to your photos. These photos will be printed for you for your one-on-one interview.

- If you are using a disposable camera, you will be asked to briefly meet with the researcher to give them the camera. You will also be asked to briefly meet with the researcher after your photos have been taken, so that these photos will be printed for you for your one-on-one interview. Please ensure that the camera is given back to the researcher approximately one-week prior to your scheduled interview to guarantee that photos will be developed in time for your one-on-one interview.

- Your photos will be developed for you at no cost.

\section{Reflections}

- Participants not using a disposable camera: You will be asked to write a brief (2-3 sentences) reflection of each photo prior to your one-on-one interview. Specifically, you will reflect on how each photo represents resistance, resilience, and/or strength to you. You will be asked to bring these reflections with you to your one-on-one interview.

- Participants using a disposable camera: At the beginning of your one-on-one interview, you will be given hard copies of your photos. You will then be asked to select 5 of your favourite photos from the photos you took with the camera. You will then be asked to write a brief (2-3 sentences) reflection of each photo. Specifically, you will reflect on how each photo represents resistance, resilience, and/or strength to you.

\section{One-on-One Interview}

- In a one-on-one interview session with the researcher, you will be asked to share your experiences and stories of gender-based violence.

- You will be asked to share the reasons you have selected each of your photos.

- You will be asked to underline action words within your reflections.

- The expected duration of the interview is two hours; however, the participant will be able to decide how long they are comfortable talking for.

- The interview will take place at a mutually agreed upon location which ensures privacy. However, the interview cannot take place at your residence.

- Participants can expect interview questions such as the following: 
May you please tell me how this photo represents your story of resistance, resilience, and/or strength?

May you please tell me the ways in which you have demonstrated resistance, resilience, and/or strength within these contexts?

May you please tell me your story of gender-based violence? Please feel free to share or omit any details according to your comfort level.

\section{RESEARCH DISSEMINATION}

Participation in this study will further the scholarship on gender-based violence through potential conference presentations, exhibition opportunities, and/or journal publications. You can access the results of this study at your own discretion by clicking the following link to the Ryerson Digital Repository where all Major Research Papers (MRP) will be uploaded upon completion:

https://digital.library.ryerson.ca/islandora/search/*\%3A*?f[0]=mods extension degree depart ment $\mathrm{ms} \% 3 \mathrm{~A} \% 22$ Social $\% 20$ Work $\% 22$

\section{POTENTIAL BENEFITS:}

Potential benefits include the opportunity for participants to reposition and reconceptualize their experiences of gender-based violence through centring their stories of resistance, resilience, and strength. In doing so, participants will actively disrupt dominant ideas of female survivors of violence as "vulnerable victims" by constructing new narratives about themselves as strong, resilient women. However, I cannot guarantee that you will receive any other personal benefits from participating in this study.

\section{WHAT ARE THE POTENTIAL RISKS TO YOU AS A PARTICIPANT:}

During the interview, you may experience some discomfort due to questions asked about personal experiences of gendered violence. Sharing these experiences may be difficult and may result in feeling upset or uncomfortable. There is some potential for psychological risk when sharing traumatic experiences. Please be assured that your participation is completely voluntary. You can take breaks, decline to answer any question at any time, and/or stop participation, either temporarily or permanently. The researcher will provide you with a list of resources at the beginning of the interview process that you may consult with at your convenience.

You may be an acquaintance of the researcher and you may have received an email from the researcher regarding the study. Please be reminded that your participation is completely voluntary and you can withdraw at any time. If you refuse to participate, this will not have any consequence for the nature of the already-existing relationship with the researcher. 
There are limitations to confidentiality. As a social worker, the researcher has an ethical responsibility of duty to report child abuse and/or neglect and risk of harm. While sharing stories of gendered violence, you may disclose that you are currently experiencing violence and your children have witnessed or have also experienced the violence within the family context. You will be reminded of these limitations of confidentiality prior to the interview. Please be reminded that you can withdraw from the study at any time.

There is low/minimal risk for personal identity being revealed (e.g. participant being identified either directly or inadvertently). Measures will be taken to protect your identity. Please see below ("Confidentiality") for a detailed description of how this risk will be managed.

\section{CONFIDENTIALITY:}

Participation in this research will be kept strictly confidential and measures will be taken to protect your identity. Pseudonyms (fake names) will be assigned to participants and any other identifying information will be censored.

Any information provided by you will only be viewed by the researcher and, if required, their supervisor; however, no identifying information will be shared. When developing your photos (digital and film), identifying information will not be shared. As stated above, please avoid taking photographs of people or anything specific that may accidentally identify yourself or others. When sharing your photos via Dropbox, only the researcher will be able to see your photos. Identifying information will not be accessible to any other parties except when required by law, such as when there are reasonable suspicions of child abuse and/or neglect or risk of harm.

The interview will be audio recorded on a password-protected audio recorder. The audio will then be transferred to a password-protected computer and, at this time, the audio file on the recorder will be destroyed. The audio file will be deleted from this password-protected computer after transcription and verification. Transcripts and participant contact information list will be password-protected and destroyed when research has completed in August 2019. You can access the final copy of the research by clicking the link above (please see "Research Dissemination") to the Ryerson Digital Repository where all MRPs will be uploaded upon completion.

Digital photos sent to the researcher will be stored in a password-protected computer. Hard copies of participant photos will be stored in a locked filing cabinet. With your permission, one or more of your photos will be included in publications and course-work based on this study. Unused photographs will be destroyed once research is completed in August 2019.

Signed consent forms and and participant reflections will also be stored in a locked filing cabinet. These will be shredded in August 2019 after the research study has completed.

\section{INCENTIVES FOR PARTICIPATION:}


Incentive to participate in the study will include printed copies of their own photos, as well as a \$10 Walmart gift card.

\section{COSTS TO PARTICIPATION:}

Reimbursement of TTC transportation (cash value equivalent to two single rides) to attend the one-to-one interview (and to pick up a disposable camera if needed) may be provided at the request of the research participant.

\section{VOLUNTARY PARTICIPATION AND WITHDRAWAL:}

Participation in this study is completely voluntary. You can choose whether to be in this study or not. If any questions make you uncomfortable, you can skip that question. You may stop participating at any time and you will still be given incentives and reimbursement as described above. If you choose to stop participating, your data will be removed from the study unless you have explicitly consented to include it. Please indicate this choice to me by May 1, 2019. Your choice of whether or not to participate will not influence your future relations with Ryerson University or the investigator, Nicole Fontyn, involved in the research.

\section{QUESTIONS ABOUT THE STUDY:}

If you have any questions about the research now, please ask. If you have questions later about the research, you may contact:

Nicole Fontyn

Researcher, MSW Candidate

nicole.fontyn@ryerson.ca

\section{Samantha Wehbi \\ Supervisor \\ swehbi@,ryerson.ca}

This study has been reviewed by the Ryerson University Research Ethics Board. If you have questions regarding your rights as a participant in this study please contact:

Research Ethics Board

c/o Office of the Vice President, Research and Innovation

Ryerson University

350 Victoria Street

Toronto, ON M5B 2K3

416-979-5042

rebchair@ryerson.ca 


\section{GENDER-BASED VIOLENCE: STORIES OF RESISTANCE, RESILIENCE, AND STRENGTH THROUGH PHOTOGRAPHY}

\section{CONFIRMATION OF AGREEMENT:}

Your signature below indicates that you have read the information in this agreement and have had a chance to ask any questions you have about the study. Your signature also indicates that you agree to participate in the study and have been told that you can change your mind and withdraw your consent to participate at any time. You have been given a copy of this agreement.

You have been told that by signing this consent agreement you are not giving up any of your legal rights.

Name of Participant (please print)

Signature of Participant

Date

I agree to be audio-recorded for the purposes of this study. I understand how these recordings will be stored and destroyed.

Signature of Participant

Date

I agree to have one or more of my photographs used for the purposes of this study. I understand how these images will be stored and destroyed.

Signature of Participant

Date 


\section{Ryerson University}

\section{RESEARCH PARTICIPANTS NEEDED!}

Are you a survivor of gender-based violence? Would you like to share your story of resistance?

What: A 2-hour interview sharing your story of resistance, resilience, and/or strength in regards to gender-based violence against women. For the purpose of this study, gender-based violence is defined as any form of violence (physical, emotional, verbal, psychological, financial, sexual, and/or systemic) perpetrated against women.

Participants will also be asked to take photos of things that represent their story prior to their interview, as well as a few brief written reflections. The 2-hour interview will explore the relationship between your stories, photos, and the wider socio-political contexts.

Purpose: To centre survivors' stories of resistance, resilience, and strength within the context of gender-based violence.

Where: A mutually agreed upon location between the participant and the researcher, which ensures privacy (Note: Interviews should not take place at your residence)

Who: To participate, you must meet the following criteria:

- Self-identify as female,

- Previous experience with gender-based violence,

- $18+$ years old

- Currently living in the Greater Toronto Area (GTA)

Compensation: In appreciation of your time, each participant will receive reimbursement for TTC transportation (cash value equivalent to two single rides), hard copies of their photographs, as well as a $\$ 10$ Walmart gift card. 
Participation in this study is completely voluntary. You can choose whether to be in this study or not. You may stop participating at any time and you will still be given compensation and reimbursement as described above.

For more information or to participate, please email the Primary Investigator, Nicole Fontyn, at nicole.fontyn@,ryerson.ca.

This study has been approved by the Ryerson Research Ethics Board (REB file number: 2018-445) and is being conducted by a graduate student as a requirement for program completion. Research supervisor can be reached at swehbi@,ryerson.ca. 


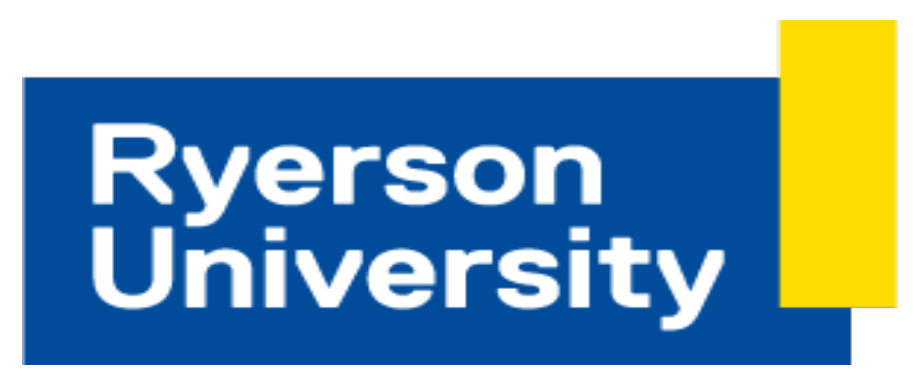

\section{GENDER-BASED VIOLENCE AGAINST WOMEN: STORIES OF RESISTANCE, RESILIENCE, AND STRENGTH THROUGH PHOTOGRAPHY}

\section{Nicole Fontyn}

\section{Recruitment Email Script to Acquaintances}

Hello,

As you may know, I am currently attending Ryerson University to complete my Master of Social Work (MSW) degree. I am seeking volunteers for a research study I am working on. This research study will explore survivors' stories of resistance, resilience, and strength within the context of gender-based violence against women. I am contacting you to see if you might be interested in participating in this research study. To participate, you need to identify as a woman who is $18+$ years old, have experience with gender-based violence, and currently living in the Greater Toronto Area (GTA). For the purpose of this study, gender-based violence is defined as any form of violence (physical, emotional, verbal, psychological, financial, sexual, and/or systemic) perpetrated against women.

This research study is being conducted as a requirement for program completion and will be supervised by Dr. Samantha Wehbi. The research will address the following question: In what ways do survivors of gendered violence demonstrate strength, resilience, and resistance at both individual and systemic levels?

If you agree to volunteer, you will be asked to take photos of objects, places, artwork, etc. that represent your story of resistance, resilience, and/or strength, followed by a few brief reflections on these photos. You will also be asked to participate in a 2-hour interview, which could be shorter depending on your comfort level.

In appreciation of your time, you will receive reimbursement of TTC fares (cash value equivalent to two single rides), hard copies of your photographs, and a $\$ 10$ Walmart gift card.

This research has been reviewed and approved by the Ryerson University Research Ethics Board (REB file number: 2018-445). 
Participation in this study is completely voluntary and there will be no repercussions should you decline this offer or choose to withdraw from the study. Please be assured that I will not be sending future emails and that it is ultimately up to you should you choose to participate in the study. If you are interested in learning more about this study or would like to participate, please reply to this email.

Thank you,

Nicole Fontyn 


\title{
APPENDIX E. INTERVIEW GUIDE
}

\section{GENDER-BASED VIOLENCE AGAINST WOMEN: STORIES OF RESISTANCE, RESILIENCE, AND STRENGTH THROUGH PHOTOGRAPHY}

\section{Nicole Fontyn}

\section{Introduction}

\author{
Interview Guide
}

Thank you for agreeing to participate in this study. The purpose of this study is to explore stories of resistance, resilience, and strength amongst survivors of gender-based violence. Please be reminded that your participation is completely voluntary. We can stop the interview at any point, take breaks if required, and you can decline to answer any questions at any time. Do you have any questions before we start?

\section{Participants Using Disposable Cameras}

Can you please select 5 of your favourite photographs?

Can you please write a brief (2-3 sentence) descriptive reflection of each photo?

\section{Opening Questions: Reflecting on Photos}

In your reflective descriptions, can you please underline words that you believe signify action?

What does this photo mean to you?

How does this photo represent your story of resistance, resilience, and/or strength?

\section{Background \& Context Questions}

Can you please tell me your story of gender-based violence? Please feel free to share or omit any details depending on your comfort level.

\section{Follow up question}

Can you please share your experiences of accessing both formal and informal services and supports?

\section{Resistance/Resilience/Strength}

Reflecting on your experiences of gender-based violence, in what ways do you think you have demonstrated resistance, resilience, and/or strength?

\section{Potential Probing questions}

What gives you hope? 
What makes you happy?

What makes you feel good about yourself and your life?

How have you overcome the challenges/barriers you have experienced?

In what ways do you think you have made positive changes in your life?

In what ways do you think you have challenged your experiences of abuse?

How have you challenged service providers that you feel did not adequately support you?

\section{Concluding Remarks}

Thank you for sharing your time and experiences with me. Is there anything else you would like to add that you have not shared yet? 


\section{APPENDIX F. PARTICIPANT RESOURCES}

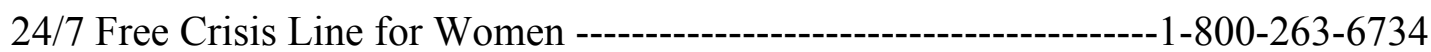

Anduhyaun Emergency Shelter -------------------------------------------416-920-1492

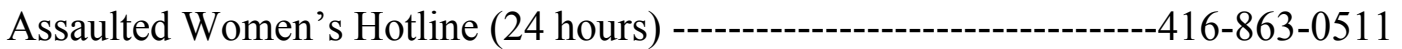

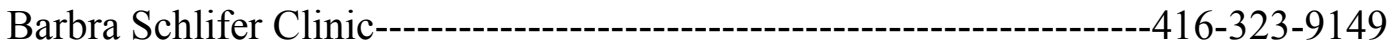

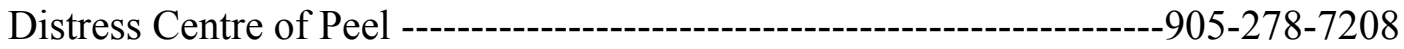

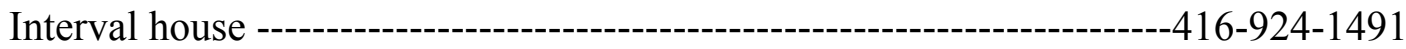

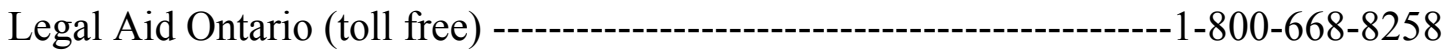

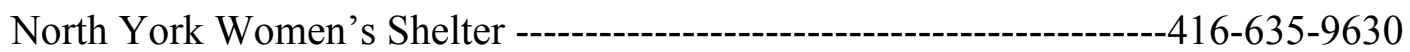

Region of Peel Emergency Housing Crisis Line-----------------------------905-272-7061 (24 hours)

Ryerson University,

The Office of Sexual Violence Support and Education-----------416-979-5000 x. 3596

Safe Centre of Peel (SCoP)----------------------------------------905-450-4650

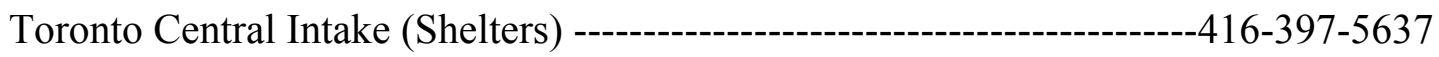

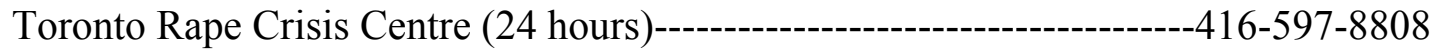

Trillium Health Partners

Sexual Assault/Domestic Violence Services ------------------905-848-7580 x. 2548

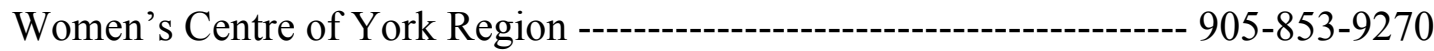

Women's College Hospital

Sexual Assault/Domestic Violence Care Centre--------------------416-323-6040 


\section{$\begin{array}{ll}\text { Research } \\ \text { Ryerson } & \text { Ethics Board }\end{array}$ University}

To: Nicole Fontyn

Re: REB 2018-445: Gender-based violence against women: Stories of resistance, resilience, and strength through photography

Date: January 18, 2019

Dear Nicole Fontyn,

The review of your protocol REB File REB 2018-445 is now complete. The project has been approved for a one year period. Please note that before proceeding with your project, compliance with other required University approvals/certifications, institutional requirements, or governmental authorizations may be required.

This approval may be extended after one year upon request. Please be advised that if the project is not renewed, approval will expire and no more research involving humans may take place. If this is a funded project, access to research funds may also be affected.

Please note that REB approval policies require that you adhere strictly to the protocol as last reviewed by the REB and that any modifications must be approved by the Board before they can be implemented. Adverse or unexpected events must be reported to the REB as soon as possible with an indication from the Principal Investigator as to how, in the view of the Principal Investigator, these events affect the continuation of the protocol.

Finally, if research subjects are in the care of a health facility, at a school, or other institution or community organization, it is the responsibility of the Principal Investigator to ensure that the ethical guidelines and approvals of those facilities or institutions are obtained and filed with the REB prior to the initiation of any research.

Please quote your REB file number (REB 2018-445) on future correspondence.

Congratulations and best of luck in conducting your research.

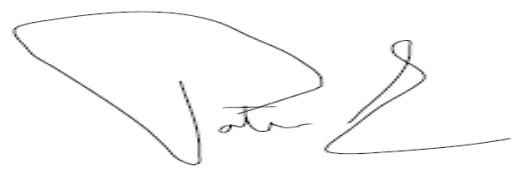

Dr. Patrizia Albanese, PhD

Chair, Ryerson University Research Ethics Board

The Following protocol attachments have been reviewed and approved. 
- Appendix C Recruitment Email Script.docx (submitted on: 22 Nov 2018)

- Appendix E Participant Resources.docx (submitted on: 22 Nov 2018)

- Appendix B Recruitment Flyer.docx (submitted on: 22 Nov 2018)

- Appendix A Consent Form.docx (submitted on: 22 Nov 2018)

- Appendix F References.docx (submitted on: 22 Nov 2018)

- Appendix D Interview Guide.docx (submitted on: 22 Nov 2018)

- Appendix A REVISED Consent Form Version 2.docx (submitted on: 09 Jan 2019)

- Appendix D REVISED Interview Guide Version 2.docx (submitted on: 09 Jan 2019)

- Appendix B REVISED Recruitment Flyer Version 2.docx (submitted on: 09 Jan 2019)

- FONTYN_CommentstoChair.docx (submitted on: 09 Jan 2019)

- Appendix C REVISED Recruitment Email Script Version 2.docx (submitted on: 09 Jan 2019)

- FONTYN_CommentsToChair2.docx (submitted on: 15 Jan 2019)

- Appendix C REVISED Recruitment Email Script Version 3.docx (submitted on: 15 Jan 2019)

- Appendix A REVISED Consent Form Version 3.docx (submitted on: 15 Jan 2019)

- Appendix B REVISED Recruitment Flyer Version 3.docx (submitted on: 15 Jan 2019)

If any changes are made to the attached document throughout the course of the research, an amendment MUST be submitted to, and subsequently approved by the REB. 


\section{References}

Aghtaie, N., \& Gangoli, G. (Eds.). (2014). Understanding gender based violence: National and international contexts. Retrieved from https://ebookcentral-proquestcom.ezproxy.lib.ryerson.ca

Ajandi, J. "Single mothers by choice": Disrupting dominant discourses of the family through social justice alternatives. International Journal of Child, Youth and Family Studies, 3 $\& 4,410-431$.

Association for Women's Rights in Development. (2004). Intersectionality: A tool for gender and economic justice. Retrieved from Women's Rights and Economic Change: www.awid.org/publications/primers/intersectionality en.pdf

Baker, T. \& Lewis, S. (2013). Responses to online photographs of non-suicidal self-injury: A thematic analysis. Archives of Suicide Research, 17, 223-235.

Banks, M. (2001). Visual methods in social research. Thousand Oaks, CA: Sage.

Belcourt, C. (2017). Indigenous art, culture and resistance: An evening with Christi Belcourt. Presented at Ryerson University Social Justice Week, Toronto, Ontario.

Bhattacharya, H. (2009). Performing silence: Gender, violence, and resistance in women's narratives from Lahaul, India. Qualitative Inquiry, 15(2), 359-371.

Bradshaw, S., Chant, S. \& Linneker, B. (2017). Gender and poverty: What we know, don’t know, and need to know for Agenda 2030. Gender, Place \& Culture, 24 (12), 1667-1688. 
Butterwick. S. (2017). The contributions of political fashion shows and fabric to visual artsbased practice. New Directions for Adult and Continuing Education, 154, 71-81.

Cannon, C., Lauve-Moon, K. \& Buttell, F. (2015). Re-theorizing intimate partner violence through post-structural feminism, queer theory, and the sociology of gender. Soc. Sci, 4, 668-687.

Chantler, K. (2006). Independence, dependency and interdependence: Struggles and resistance of minoritized women within and on leaving violence relationships. Feminist Review, $82,27-49$.

Coholic, D., Cote-Meek, S., \& Recollet, D. (2013). Exploring the acceptability and perceived benefits of arts-based group methods for Aboriginal women living in an urban community within Northeastern Ontario. Canadian Social Work Review, 29 (2), 149-168.

Corcoran, L. \& Lane, A. (2018). Exploring the impact of off the beaten path: Violence, women, and art. Women's Studies International Forum, 67, 72-79.

Crann, S. \& Barata, P. (2016). The experience of resilience for adult female survivors of intimate partner violence: A phenomenological inquiry. Violence Against Women, 22 (7), 853-875.

Damianakis, T. (2007). Social work's dialogue with the arts: Epistemological and practice intersections. Families in Society, 88 (4), 525-532. 
Drumm, R., Popescu, M., Cooper, L., Trecartin, S., Seifert, M., Foster, T. \& Kilcher, C. (2014). "God just brought me through it": Spiritual coping strategies for resilience among intimate partner violence survivors. Clin Social Work J, 42, 385-394.

Duffy, L. (2015). Achieving a sustainable livelihood after leaving intimate partner violence: Challenges and opportunities. Journal of Family Violence, 30(4), 403-417.

Edwards, K., Probst, D., Tansill, E., Dixon, K., Bennett, S. \& Gidycz, C. (2014). In their own words: A content-analytic study of college women's resistance to sexual assault. Journal of Interpersonal Violence, 29(14), 2527-2547.

Fook, J. (2012). Chapter 4. Power In J. Fook, Social work: Critical theory and practice (pp. 5364). Thousand Oaks: Sage Publications.

Fraser, H. \& Jarldon, M. (2015). Narrative research and resistance: A cautionary tale. In L. Brown \& S. Strega. Research as Resistance: Revisiting Critical, Indigenous, and AntiOppressive Approaches (pp. 153-175). Toronto, ON: Canadian Scholars’ Press.

Frohmann, L. (2005). The framing safety project: Photographs and narratives by battered women. Violence Against Women, 11(11), 1369-1419. doi: 10.1177/1077801205280271

Goodman, L., Dutton, M., Vankos, N. \& Weinfurt, K. (2005). Women's resources and use of strategies as risk and protective factors for reabuse over time. Violence Against Women, 11 (3), 311-336. doi: 10.1177/1077801204273297.

Gray, M., \& Schubert, L. (2010). Turning base into gold: Transmuting art, practice, research and experience into knowledge. British Journal of Social Work, 40, 2308-2325. 
Gray, M., Dean, M., Agllias, K., Howard, A. \& Schubert, L. (2015). Perspectives on Neoliberalism for Human Service Professionals. Social Service Review, 89(2), 368-392. Hackett, S. (2019, January 24). Personal communication.

Heise, L. , Ellsberg, M. and Gottmoeller, M. (2002), A global overview of gender-based violence. International Journal of Gynecology \& Obstetrics, 78, S5-S14. doi:10.1016/S0020-7292(02)00038-3.

Hollander, J. (2005). Challenging despair: Teaching about women's resistance to violence. Violence Against Women, 11(6), 776-791.

Hollander, J. \& Rodgers, K. (2014). Constructing victims: The erasure of women's resistance to sexual assault. Sociological Forum, 29(2), 342-364.

Humphreys, C. \& Absler, D. (2011). History repeating: Child protection responses to domestic violence. Child and Family Social Work, 16, 464-473.

Jacinto, G. A., Turnage, B.F. \& Cook, I. (2010). Domestic violence survivors: Spirituality and social support. Journal of Religion \& Spirituality in Social Work: Social Thought, 29, $109-123$.

Jackson, D. \& Mannix, J. (2004). Giving voice to the burden of blame: A feminist study of mothers' experiences of mother blaming. International Journal of Nursing Practice, 10, $150-158$. 
Jaquier, V., Fisher, B. \& Johnson, H. (2011). Prevalence and risks of physical and sexual violence against women by nonintimates: An exploratory study across nine countries. Victims and Offenders, 6, 399-415.

Johnson, H. (2017). Why doesn't she just report it?: Apprehensions and contradictions for women who report sexual violence to the police. Canadian Journal of Women and Law, 19 (1), 36-59.

Kumar, A., Nizamie, H., \& Srivasta, N. (2013). Violence against women and mental health. Mental Health \& Prevention, 1, 4-10.

Lee, J. (2008). Survivors of gendered violence in the feminist classroom. Violence Against Women, 14(12), 1451-1464.

Lu, L. \& Yuen, F. (2012). Journey women: Art therapy in a decolonizing framework of practice. The Arts in Psychotherapy, 39, 192-200.

Mandel, D. (2010). Child welfare and domestic violence: Tackling the themes and thorny questions that stand in the way of collaboration and improvement of child welfare practice. Violence Against Women, 16(5), 530-536.

McArdle, F., Knight, L., \& Stratigos, T. (2013). Imagining social justice. Contemporary Issues in Early Childhood, 14(4), 357-369.

McInturff, K. (2013). The gap in the gender gap: Violence against women in Canada [E-reader Version]. Retrieved from 
http://www.policyalternatives.ca/sites/default/files/uploads/publications/National\%20Offi ce/2013/07/Gap in Gender Gap VAW.pdf.

McKenzie-Mohr, S. \& Lafrance, M. (2017). Narrative resistance in social work research and practice: Counter-storying in the pursuit of social justice. Qualitative Social Work, 16(2), 189-205.

McLaren, H. (2012). (Un)-blaming mothers whose partners sexually abuse children: In view of heteronormative myths, pressures and authorities. Child and Family Social Work, 18, $439-448$.

Moffatt, K. (1999). Surveillance and government of the the welfare recipient. In A. Chambon, A. Irving, \& L. Epstein, Reading Foucault for Social Work (pp. 219-242). New York : Columbia University Press.

Moffatt, K. (2010). Social work and the creative arts. Canadian Social Work Review, 26 (2), 213-215.

Moffatt, K. (in press). Postmodern Social Work, Reflective Practice and Education. New York: Columbia University Press.

Morley, C. \& Macfarlane, S. (2012). The nexus between feminism and postmodernism: Still a central concern for critical social work. British Journal of Social Work, 42, 687-705.

Morrow, M., Havinsky, O., \& Varcoe, C. (2004). Women and violence: The effects of dismantling the welfare state. Critical Social Policy, 24(3), 358-384. 
Mura, K. E. \& McMillin, L. A. (1996). Not a damsel in distress: Feminist medieval studies at a small library arts university. Feminist Teacher, 10(2), 49-58.

Pierce, G. (2010). Poststructural feminist pedagogy in a post-Katrina world. Feminist Teacher, 21(1), 36-53.

Pajak, C., Ahmad, F., Jenney, A., Fisher, P. \& Chan, L. (2014). Survivor's cost of saying no: Exploring the experience of accessing services for intimate partner violence. Journal of Interpersonal Violence, 29 (4), 2571-2591.

Pedersen, J., Malcoe, L. \& Pulkingham, J. (2013). Explaining aboriginal/non-aboriginal inequalities in postseparation violence against Canadian women: Application of a structural violence approach. Violence Against Women, 19(8), 1034-1058.

Pyles, L. \& DeChiro, J. (2012). Building bridges to safety and justice: Stories of survival and resistance. Journal of Women and Social Work, 27(1), 84-94.

Romans, S., Forte, T., Cohen, M., Du Mont, J. \& Hyman. I. (2007). Who is most at risk for intimate partner violence? A Canadian population-based study. Journal of Interpersonal Violence, 22(12), 1495-1514.

Rose, G. (2012). Visual methodologies: An introduction to researching with visual materials. ( $3^{\text {rd }}$ ed.). Los Angeles, CA: Sage.

Simmonds, S., Roux, C. \& Avest, I. (2015). Blurring the boundaries between photovoice and narrative inquiry: A narrative-photovoice methodology for gender-based research. International Journal of Qualitative Methods, 14(3), 33-49. 
Sinding, C., Warren, R., \& Paton, C. (2014). Social work and the arts: Images at the intersection. Qualitative Social Work, 13(2), 187-202.

Soyini Madison, D. (2005). Introduction to critical ethnography: Theory and method. In Critical ethnography: Method, ethics and performance (pp. 1-16). Thousand Oaks, CA: Sage.

Stevenson, M. \& Allen, A. (2017). Women's empowerment: Finding strength in selfcompassion. Women \& Health, 57(3), 295-310.

Strega, S. (2005). The view from the post-structural margins: Epistemology and methodology reconsidered, In S. Strega \& L. Brown (eds.). Research as Resistance: Revisiting Critical, indigenous, and Anti-oppressive Approaches ( $2^{\text {nd }}$ ed), pp. 119-152. Toronto: Canadian Scholars' Press.

Taylor, S. R. (2018). The body is not an apology: The power of radical self-love. Oakland, CA: Berrett-Koehler Publishers.

Vacchelli, E. \& Peyrefitte, M. (2018). Telling digital stories as feminist research and practice: A 2-day workshop with migrant women in London. Methodological Innovations, 11(1), $1-11$.

Wehbi, S. (2015). Arts-informed teaching practice: Examples from a graduate anti-oppression classroom. Social Work Education, 34(1), 46-59. 
Wehbi, S. (2017). The use of photography in anti-oppressive research. In Parada, H. \& S. Wehbi (Eds.), Reimagining anti-oppression social work research (pp. 39-46). Toronto, ON: Canadian Scholars.

Wood, L. (2015). Hoping, empowering, strengthening: Theories used in intimate partner violence advocacy. Journal of Women and Social Work, 30(3), 286-301. 